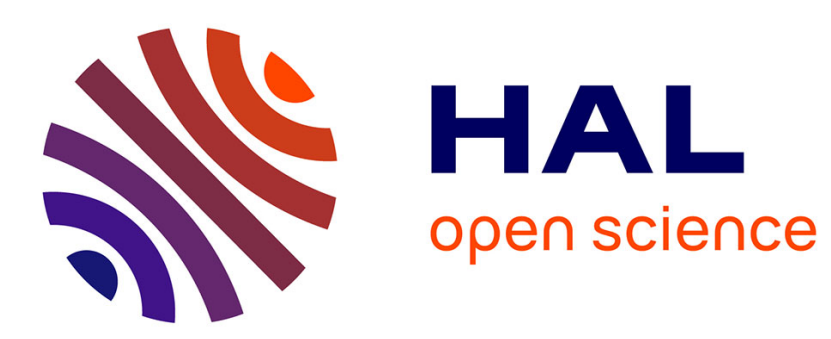

\title{
Electrochemical determination of traces lead ions using a new nanocomposite of polypyrrole/carbon nanofibers
} Larbi Oularbi, Mireille Turmine, Mama El Rhazi

\section{To cite this version:}

Larbi Oularbi, Mireille Turmine, Mama El Rhazi. Electrochemical determination of traces lead ions using a new nanocomposite of polypyrrole/carbon nanofibers. Journal of Solid State Electrochemistry, 2017, 21, pp.3289-3300. 10.1007/s10008-017-3676-2 . hal-01609286

\section{HAL Id: hal-01609286 \\ https://hal.sorbonne-universite.fr/hal-01609286}

Submitted on 3 Oct 2017

HAL is a multi-disciplinary open access archive for the deposit and dissemination of scientific research documents, whether they are published or not. The documents may come from teaching and research institutions in France or abroad, or from public or private research centers.
L'archive ouverte pluridisciplinaire HAL, est destinée au dépôt et à la diffusion de documents scientifiques de niveau recherche, publiés ou non, émanant des établissements d'enseignement et de recherche français ou étrangers, des laboratoires publics ou privés. 
Electrochemical determination of traces lead ions using a new nanocomposite of polypyrrole/carbon nanofibers

Larbi OULARBI ${ }^{\mathrm{a}, \mathrm{b}}$, Mireille TURMINE ${ }^{\mathrm{b}}$, Mama EL RHAZI ${ }^{\mathrm{a}}{ }^{*}$

a University Hassan II Casablanca, Faculty of Science and Technology, Laboratory of Materials Membranes and Environment, P.B 146, Mohammedia 20800, Morocco

b Sorbonne University, UPMC University Paris 06, CNRS, Laboratoire Interfaces et Systèmes Electrochimiques, 4 place Jussieu, F-75005, Paris, France

\section{Corresponding author:}

Mama El Rhazi (Faculty of Sciences and Technologies -BP 146 Mohammedia 20650, University Hassan II of Casablanca, Morocco)

*elrhazim@ hotmail.com

Tel: 212523315352 Fax: 212523315353 


\begin{abstract}
In this paper, a new nanocomposite of polypyrrole (PPy) and carbon nanofibers (CNFs) modified carbon paste electrode (CPE) has been reported for the determination of traces lead ions $\left(\mathrm{Pb}^{2+}\right)$. The obtained nanocomposite was fabricated by combining the unique advantages of PPy and CNFs using a very simple approach, which consists on modifying the CPE by the functionalized CNFs and then by the PPy film using galvanostatic mode. Several techniques were used to investigate the functionalized CNFs and the PPy/CNFs nanocomposite including Fourier transform infrared spectroscopy (FTIR) and X-ray diffraction (XRD) for surface layers of CNFs, cyclic voltammetry (CV) and electrochemical impedance spectroscopy (EIS) for the electrical proprieties of the PPy/CNFs nanocomposite. The surface morphologies were examined by field emission gun scanning electron microscopy (FEG-SEM). The square wave anodic striping voltammetry (SWASV) was used to investigate the analytical performances of the designed electrode PPy/CNFs/CPE. Different parameters that affect the stripping analysis of $\mathrm{Pb}^{2+}$ including supporting electrolyte, deposition potential, and deposition time were investigated. Under the optimum experimental conditions, a good linearity between the stripping peak currents and the concentration of $\mathrm{Pb}^{2+}$ was obtained in the range of concentration from 0.2 to $130 \mu \mathrm{g} \mathrm{L}^{-1} \mathrm{~Pb}^{2+}$. The detection limit was estimated to be $0.05 \mu \mathrm{g} \mathrm{L}^{-1} \mathrm{~Pb}^{2+}$. Finally, the proposed method has been successfully applied for the determination of $\mathrm{Pb}^{2+}$ in real samples of tap water with satisfactory results.
\end{abstract}

Keywords: Polypyrrole; Carbon nanofibers; Carbon paste electrode; Lead ions; Square wave voltammetric 


\section{Introduction}

Nanocomposites are a class of materials, formed by combining multiple phases at nonmetric scale, with the aim to produce new materials with interesting proprieties. Over the last decades nanocomposites based on carbon nanomaterials (CNMs) including carbon nanotubes (CNTs), graphene (GR) and carbon nanofibers (CNFs) combined with conducting polymers (CPs) such as polypyrrole (PPy), polyaniline (PANi), polythiophene (PTh), and poly(3,4-ethylenedioxythiophene) (PEDOT) have opened a new era in the field of nanoscience and nanotechnology [1]. More recently, CNMs/CPs nanocomposites have received considerable attention as sensing materials due to their extraordinary proprieties mainly including excellent electrical conductivities, large active surface area and stability [2]. Monitoring and control of environmental pollution are fields that these nanocomposites have been extensively used as sensors to analyze a variety of pollutants such as heavy metals ions $\left(\mathrm{Pb}^{2+}, \mathrm{Cd}^{2+}, \mathrm{Hg}^{2+}\right)$ and pesticides [3, 4]. In addition, to overcoming the new challenges posed by different samples matrices. Traces detection of heavy metals ions in water is necessary due to high toxicity and serious risks posed by these pollutants for environmental and human health. Among of them, lead ions $\left(\mathrm{Pb}^{2+}\right)$ is one of the most toxic heavy metals ions even at a low concentration exposition [5, 6]. Considerable efforts have been paid to develop a simple and a highly sensitive analytical methods for the analysis of lead ions and many other heavy metals in water $[7,8]$. Electrochemical methods including square wave anodic stripping voltammetry (SWASV) using modified electrodes provide more attractive feature as suitable tools in the sensing applications, due to their great potentials which are easy to operate, low cost, high sensitivity, and selectivity [9]. Several research works have reported the use of electrochemical methods and CNMs/CPs nanocomposite modified electrodes as sensing platform for heavy metals ions. Graphene film electrode modified with PANi and bismuth nanoparticles was used to detect traces of $\mathrm{Cd}^{2+}$ and $\mathrm{Pb}^{2+}$ using SWASV [10]. A nanocomposite of multi-walled carbon nanotubes/poly(1,5- 
diaminonaphthalene) (MWCNT/P-1,5-DAN) modified platinum electrode was reported for the estimated around of 3.2 and $2.1 \mu \mathrm{g} \mathrm{L}^{-1}$ respectively for $\mathrm{Cd}^{2+}$ and $\mathrm{Pb}^{2+}$ [11]. Another nanocomposite of P-1,5-DAN and reduced graphene oxide (rGO) modified platinum patterned electrode was fabricated and used for $\mathrm{Pb}^{2+}$ determination. The detection limit of $\mathrm{Pb}^{2+}$ using the P-1,5-DAN/rGO/Pt was equal to $0.2 \mu \mathrm{g} \mathrm{L}^{-1}$ [12]. PPy and carbonaceous nanospheres (CNSs) modified screen-printed electrode (SPE) was also fabricated for a selective detection of $\mathrm{Hg}^{2+}$ and $\mathrm{Pb}^{2+}$ using SWASV [13]. PPy and reduced graphene oxide (rGO) modified glassy carbon electrode (GCE) was reported as a new nanocomposite electrode for a high selective detection of $\mathrm{Hg}^{2+}$ [14]. Cysteine functionalized graphene oxide (sGO) and polypyrrole modified screen printed electrode (SPE) was reported and applied for the determination of $\mathrm{Pb}^{2+}$ using differential pulse anodic striping voltammetry (DPASV) [15]. GCE modified with MWCNTs functionalized 2-(5-bromo-2-pyridylazo)-5-diethylminophenol (MWCNTs/5-Br-PADAP) was prepared to fabricate a new electrochemical sensor for $\mathrm{Pb}^{2+}$ determination using DPASV [16]. Carbon paste electrodes (CPEs), have been widely used in a variety of electrochemical applications due to their interesting properties such as a low background current, low cost, a simple preparation and renewal of the surface [17]. However, the use of these electrodes as sensors requires an improvement of their properties. Chemically modified carbon paste electrodes (CMCPEs) have been introduced as a suitable approach to improve their analytical performances mainly including the sensitivity, selectivity, stability, and detection limit [18-21]. The CMCPEs consist of the modification of the surface of CPE by various materials such as metals nanoparticles (MNPs), CNMs, and CPs [22-24]. The combination of these materials was also applied to combine their fantastic proprieties. The resulting modified electrodes could be used for the analysis of several analytes including heavy metals ions, pesticides, and many other compounds [25-27]. 
Vapor grow carbon nanofibers (VGCNFs) or simply (CNFs) are a class of carbon nanomaterials

with a cylindrical nanostructure of graphene layers arranged as stacked cones, cups or plates [28-30]. CNFs are recognized by their remarkable properties including excellent electrical and thermal conductivities, high chemical and mechanical stability, good specific surface area and a possibility of mass production. These properties make CNFs a very promising nanomaterial in various application area [31-34]. However, few studies have reported their application in electrochemical sensors.

In the present work a new nanocomposite of PPy/CNFs modified CPE was reported. A very simple approach was used to combine the unique properties of PPy and CNFs, consisting of the dispersion of the functionalized CNFs at the CPE surface then followed by the electropolymerization of PPy using galvanostatic mode. The PPy was used because of its remarkable properties including good electrical conductivity, high stability, and a facile synthesis. Moreover, PPy is a promising conjugated conducting polymer for the development of new electrochemical sensors, particularly for heavy metal ions. To our best knowledge, no work has been devoted to the CNFs and PPy as sensing materials for the detection of heavy metals ions. Different techniques were used to investigate the structural and electrical proprieties of the functionalized CNFs and PPy/CNFs nanocomposite including Fourier transform infrared (FTIR), X-ray diffraction (XDR), cyclic voltammetry (CV), electrochemical impedance spectroscopy (EIS), and field emission gun scanning electron microscopy (FEGSEM). The analytical performances of $\mathrm{PPy} / \mathrm{CNF} / \mathrm{CPE}$ for the determination of $\mathrm{Pb}^{2+}$ were studied using SWASV, several parameters affecting the stripping analysis were investigated. Finally, the application of the proposed method for the analysis of $\mathrm{Pb}^{2+}$ in real samples was tested with satisfactory results.

\section{Materials and methods}




\section{Chemicals and reagents}

Pyrrole Py (99\%) was obtained from ACROS Organics and purified by distillation prior to use. Vapor grow carbon nanofibers (CNFs) with diameter of $100 \mathrm{~nm}$ and length range from 20 to $200 \mu \mathrm{m}$, graphite powder (particle size less than $20 \mu \mathrm{m}$ ), paraffin oil, lithium perchlorate $\mathrm{LiClO}_{4}$ (purum p.a. $98 \%$ ), lead (II) nitrate $\mathrm{Pb}\left(\mathrm{NO}_{3}\right)_{2}$ (ACS reagent, $\geq 99 \%$ ) and potassium ferrocyanideferricyanide $\mathrm{K}_{3} \mathrm{Fe}(\mathrm{CN})_{6} / \mathrm{K}_{4} \mathrm{Fe}(\mathrm{CN})_{6} .3 \mathrm{H}_{2} \mathrm{O}$ (ACS reagent, $\geq 99 \%$ ) were obtained from Sigma Aldrich. Sulfuric acid $\mathrm{H}_{2} \mathrm{SO}_{4}(98 \%)$ was purchased from Fluka, potassium chloride $\mathrm{KCl}(99 \%)$ and nitric acid $\mathrm{HNO}_{3}(68 \%)$ from AnalaR NORMAPU. The acetate buffer solution was prepared by mixing an appropriate amounts of acetic acid sodium $\mathrm{CH}_{3} \mathrm{COONa}$ (anhydrous ACROS Organics) and acetic acid $\mathrm{CH}_{3} \mathrm{COOH}$ (Sigma Aldrich). Al other chemicals and reagents used in this study were of analytical grade.

\section{Materials and apparatus}

The electrochemical measurements were performed in a conventional three-electrodes cell containing the bare or the modified CPE as working electrode, platinum grid with a surface area of $4 \mathrm{~cm} 2$ as counter electrode and saturated calomel electrode (SCE) as reference electrode (Ref. 421, Radiometer Analytical). Voltammetry measurements including cyclic voltammetry (CV) and square wave voltammetry (SWV), were performed with an EcoChemie Autolab PGSTAT100 Potentiostat/Galvanostat under the control of GPES software, version 4.9. Electrochemical impedance measurements were performed using a potentiostat Sotelem and a frequency response analyzer (FRA, Solartron 1254) controlled by a software developed in the laboratory LISE. Fourier transform infrared spectroscopy (FTIR) were recorded with $\mathrm{KBr}$ pellets using Bruker IFS 66/S FTIR spectrometer. The X-ray diffraction (XRD) analysis were performed using a Panalytical Empyrean diffractometer equipped with a $\mathrm{Cu}-\mathrm{K} \alpha$ as radiation 
source $(\mathrm{K} \alpha=1.54 \AA)$. The surface morphology of the modified electrodes was analyzed by field emission gun scanning electron microscope (FEG-SEM, Zeiss-Supra 55).

\section{Functionalization of CNFs}

The acid treatment is a method widely used to oxidize the CNFs or CNTs by creating carboxyl (-COOH), carbonyl (-CO), and hydroxyl $(-\mathrm{COH})$ groups on their surface. In addition, this treatment could eliminate the impurities from the production process principally metal catalysts [35-37]. For that an amount of CNFs ( $1 \mathrm{~g})$ was added to a mixture solution of concentrated nitric and sulfuric acid (3:1 volume ratio) and dispersed under ultrasound during $10 \mathrm{~min}$. Then, the mixture solution was refluxed at $80{ }^{\circ} \mathrm{C}$ under magnetic stirring during $6 \mathrm{~h}$. The residue was then filtered using a membrane (Millipore polycarbonate, $0.22 \mu \mathrm{m}$ in diameter) and rinsed with bidistilled water until a neutral $\mathrm{pH}$. Finally, the obtained CNFs were dried at $60{ }^{\circ} \mathrm{C}$ during 8 hours.

\section{Preparation of modified electrodes}

Carbon paste electrode was prepared by mixing the graphite powder $(1 \mathrm{~g})$ and the paraffin oil $(300 \mu \mathrm{L})$ in a mortar until a homogeneous paste was obtained [38]. A portion of resulting paste was carefully packed into electrode cavity (Teflon tube, $3 \mathrm{~mm}$ in diameter), and then polished on a clean paper until a smooth surface was obtained. The electrical contact was established using a stainless steel rod with a diameter of $2 \mathrm{~mm}$. CNFs modified CPE was prepared by dropping $10 \mu \mathrm{L}$ of a suspension of the functionalized CNFs onto the CPE surface, which is prepared by dispersing $2 \mathrm{mg}$ of the treated CNFs in $1 \mathrm{ml}$ of the bidistilled water under ultrasonication. The obtained modified electrode was then dried at room temperature and designed CNFs/CPE. The PPy film modified bare CPE and CNFs/CPE was synthesized using galvanostatic mode in a solution of $0.1 \mathrm{M}$ pyrrole and $0.5 \mathrm{M} \mathrm{LiClO}_{4}$ at an applied constant current of $0.2 \mathrm{~mA} \mathrm{~cm}{ }^{-2}$ during 100 seconds. The modified electrodes were denoted PPy/CPE 
and PPy/CNFs/CPE thoroughly washed with bidistilled water and dried under a gentle stream of nitrogen gas.

\section{Measurement procedure}

Cyclic voltammetry (CV) measurements were performed at a potential scan rate of $50 \mathrm{mV} \mathrm{s}^{-1}$ in $0.25 \mathrm{M} \mathrm{LiClO}_{4}$, and in $10 \mathrm{mM}$ of $\left[\mathrm{Fe}(\mathrm{CN})_{6}\right]^{3-/ 4-}$ solution containing $0.5 \mathrm{M} \mathrm{KCl}$ respectively at a potential range from +0.3 to $-0.8 \mathrm{~V} / \mathrm{SCE}$ and +0.6 to $-0.4 \mathrm{~V} / \mathrm{SCE}$. Electrochemical impedance measurements were carried out in $10 \mathrm{mM}$ of $\left[\mathrm{Fe}(\mathrm{CN})_{6}\right]^{3-/ 4-}$ solution containing $0.5 \mathrm{M} \mathrm{KCl}$ at equilibrium potential in the frequency ranges from $10 \mathrm{mHz}$ to $63 \mathrm{kHz}$ and an amplitude of $10 \mathrm{mV}$. SWASV measurements were performed in $0.1 \mathrm{M}$ acetate buffer solution at $\mathrm{pH} 4.5$ containing a predetermined concentration of targets metal ions. A deposition potential of $-1.2 \mathrm{~V} / \mathrm{SCE}$ was applied to the working electrode PPy/CNFs/CPE during 600 seconds and under magnetic stirring. After a period of stabilization of about 15 seconds, the square wave voltammograms (SWVs) were recorded by applying simultaneously a frequency of $50 \mathrm{~Hz}$, step potential of $5 \mathrm{mV}$, amplitude of $50 \mathrm{mV}$, and a scan positive potential range from -0.9 to -0.3 V/SCE. To remove the possible residual metal ions on the electrode surface a potential of 0.3 V/SCE was applied to the working electrode during 15 seconds under magnetic stirring prior to the next measurement. All the experiments were carried out in a constant temperature $(25.0 \pm$ $0.1^{\circ} \mathrm{C}$ ) under nitrogen gas environment.

\section{Results and discussion}

\section{FTIR and XDR characterization of the functionalized CNFs}

FTIR spectroscopy has been widely used as a suitable investigation to identify the surface functional groups. Fig. 1a shows the FTIR spectra of CNFs before and after acid treatment. It could be seen that the treated CNFs demonstrate new bands compared to untreated CNFs which 
leading to new functional groups on their surface. The band appeared at $3430 \mathrm{~cm}^{-1}$ indicates the presence of the hydroxyl groups $(-\mathrm{OH})$, while the adsorption bands at 2864 and $2927 \mathrm{~cm}^{-1}$ are respectively assigned to symmetric and asymmetric methylene stretching bands. The bands located at 2336 and $2361 \mathrm{~cm}^{-1}$ are attributed to hydrogen bounding due to carboxylic groups $(-\mathrm{COOH})$ which are formed during the oxidation of $-\mathrm{OH}$ groups. The formation of $-\mathrm{COOH}$ groups on the treated CNFs surface could be confirmed by the appearance of a new band at $1741 \mathrm{~cm}^{-1}$, in addition to the band at $1113 \mathrm{~cm}^{-1}$ which are respectively attributed to stretching vibrations of carbonyl groups $\mathrm{C}=\mathrm{O}$ and $\mathrm{C}-\mathrm{O}$ presented in $-\mathrm{COOH}$ groups $[39,40]$. The adsorption band at $1635 \mathrm{~cm}^{-1}$ is assigned to the conjugated $\mathrm{C}=\mathrm{C}$ stretching related to $\mathrm{CNFs}$ structure. The obtained results shows clearly that the $-\mathrm{COOH}$ groups were successively created on the treated CNFs surface, which could be leads to a good dispersion and purification of CNFs [41]. XRD analysis were also used to control the crystalline structure of CNFs before and after acid treatment. The XRD patterns for the CNFs is shown in Fig. 1b, it could be seen that the CNFs shows almost a same first order diffraction peak located at $2 \theta=26^{\circ}$ which is attributed to the hexagonal structure of CNFs with a Miller indices of (002) and an experimental spacing $d$ of $3.37 \AA$ according to Bragg's equation [42]. The difference in intensity of peaks could be assigned to the different adsorption coefficients of the functional groups at the CNFs surface, in addition to the graphitization degree after the acid treatment as discussed in the literature [43]. The obtained results affirm that the treated CNFs have been no huge change in their crystalline structure.

Fig. 1 a) FTIR spectrum and b) XRD patterns of CNFs before and after acid treatment

\section{Electropolymerization of PPy and cyclic voltammetry (CV) characterization of the} modified electrodes 
Electrochemical polymerization of PPy on bare CPE and CNFs/CPE surface was performed using galvanostatic mode. Fig. 2a displays the chronopotentiometric curves obtained during the deposition of PPy. The potential decreases during the first seconds then stabilize at 0.6 and 0.5 V/SCE respectively for $\mathrm{CPE}$ and $\mathrm{CNFs} / \mathrm{CPE}$, which corresponds to the electropolymerization potential of PPy. The difference in the potential between the two electrodes could be attributed to the good electrical properties of the PPy on CNFs. It is supposed that the functional group of CNFs promoted charger transfer during the electropolymerization leading to reduction of the deposition potential. These results are in agreement with those reported by Shi and Zhitomirsky [44]. To confirm the successful synthesis of the PPy film, the modified electrodes were characterized in $0.25 \mathrm{M} \mathrm{LiClO}_{4}$ using cyclic voltammetry (CV). Fig. 2b shows the cyclic voltammograms recorded at different modified electrodes at a scan rate of $50 \mathrm{mV} \mathrm{s}^{-1}$. It could be seen that the bare $\mathrm{CPE}$ and $\mathrm{CNF} / \mathrm{CPE}$ are characterized with a very background current, while PPy film modified CPE and CNFs/CPE have shown two typical redox systems indicating that the PPy film was successfully electropolymerized on the both surfaces. However, in the presence of CNFs the anodic and cathodic peaks currents of the PPy were increased with a welldefined peaks. In addition, the peak potential separation $\left(\Delta E_{p}\right)$ was decreased, revealing the role of the CNFs to enhance the electronic properties of PPy film. These results are similar with those reported in the literature concerning the polymerization of PPy on CNTs at a constant current [45]. In order to complement our investigation, the modified electrodes were then characterized in $10 \mathrm{mM}\left[\mathrm{Fe}(\mathrm{CN})_{6}\right]^{3-/ 4-}$ solution containing $0.5 \mathrm{M} \mathrm{KCl}$. Fig. 2c shows the cyclic voltammograms recorded at different modified electrodes at a scan rate of $50 \mathrm{mV} \mathrm{s}^{-1}$. The bare CPE was characterized by a quasi-reversible redox reaction with a $\Delta E_{p}$ of about $293 \mathrm{mV}$, indicating a slow electron transfer at the CPE surface. On the CPE modified with CNFs the charge transfer rate was improved leading to a $\Delta E_{p}$ of about $110 \mathrm{mV}$, with an increase of current of about $150 \%$ compared to the bare CPE. This behavior could be attributed to the presence of 
the functionalized CNFs by providing a much active surface and an easier electron transfer [46].

PPy film modified bare CPE and CNFs/CPE have shown a significant shift of the voltammetric wave with an increase of peak current. The $\Delta E_{p}$ observed at PPy/CPE and PPy/CNFs/CPE was respectively equal to 85 and $68 \mathrm{mV}$, revealing that the PPy and PPy/CNFs films has been assembled onto the $\mathrm{CPE}$ and enhanced the electron transfer at the electrode surface. PPy/CNFs modified CPE provides a high current around 270\%, more than obtained at bare CPE, with a good faradaic redox behavior. This behavior could be attributed to good electrical and surface properties of the formed PPy/CNFs nanocomposite as reported in previous studies by combining CNMs and CPs such as PPy/CNSs [13], PPy/sGO [15] and P1,5-DAN/MWCNT [11].

Fig. 2 a) Chronopotentiometric curves of PPy on bare CPE (cyan line) and CNFs/CPE (green line) obtained at an applied constant current of $0.2 \mathrm{~mA} \mathrm{~cm}{ }^{2}$ from aqueous solution containing 0.1 M pyrrole and $0.5 \mathrm{M} \mathrm{LiClO}_{4}$. Typical cyclic voltammograms of the fabricated electrodes: bare CPE (red line), CNFs/CPE (blue line), PPy/CPE (cyan line) and PPy/CNFs/CPE (green line) recorded at scan rate of $\left.50 \mathrm{mV} \mathrm{s}^{-1} \mathbf{b}\right)$ in $\left.0.25 \mathrm{M} \mathrm{LiClO}_{4} \mathbf{c}\right)$ in $10 \mathrm{mM}\left[\mathrm{Fe}(\mathrm{CN})_{6}\right]^{3-/ 4-}$ solution containing $0.5 \mathrm{M} \mathrm{KCl}$

\section{Electrochemical impedance spectroscopy (EIS) characterization}

EIS technique is a powerful technique to investigate the interface properties of the modified electrodes. The impedance measurements were recorded out in $10 \mathrm{mM}\left[\mathrm{Fe}(\mathrm{CN})_{6}\right]^{3-/ 4-}$ solution containing $0.5 \mathrm{M} \mathrm{KCl}$ at the equilibrium potential in the range of frequency from $10 \mathrm{mHz}$ to 63 KHz. Fig. 3 shows the typical Nyquist plots achieved at different modified electrodes, and the estimated values of the charge transfer resistance $\left(R_{c t}\right)$ and the double layer capacitance $\left(C_{d l}\right)$ which are obtained by fitting the impedance data using Randles equivalent circuit. At bare CPE and CNFs/CPE it could be seen that the $R_{c t}$ decreases respectively from 32.0 to $5.9 \Omega \mathrm{cm}^{2}$ 
indicating a poor electron transfer reaction of $\left[\mathrm{Fe}(\mathrm{CN})_{6}\right]^{3-14-}$ at the bare $\mathrm{CPE}$, while the $C_{d l}$ increases respectively from 6 to $255 \mu \mathrm{F} \mathrm{cm}^{-2}$. Indeed, the presence of the non-conductive paraffin oil at the electrode surface decrease the active surface area and then the electron transfer [47]. However, the electrical properties of CPE were improved after its modification by the functionalized CNFs, inducting their role to promote the electron transfer as reported previously using CNFs and other CNMs [11, 12, 46, 48]. In the case of PPy film modified CPE and CNFs/CPE, the $\mathrm{R}_{\mathrm{ct}}$ value decreased even more compared to these electrodes before their modification. These results showed that the PPy was successfully electropolymerized on the modified electrodes and could promote the electron transfer reaction of $\left[\mathrm{Fe}(\mathrm{CN})_{6}\right]^{3-/ 4-}$ due to its interesting electronic proprieties [13]. In particular at the PPy/CNFs/CPE, the $R_{c t}$ has been further reduced and reach a value of $0.3 \Omega \mathrm{cm}^{2}$ with increase of the $C_{d l}$, indicating the improvement of conductivity of the film. This improvement is due to the contribution of the large surface area offered by CNFs during electropolymerization as reported by others authors using nanocomposite such as PPy/sGO [15], PPy/MWCNTs [49]. Based on the $R_{c t}$ and $C_{d l}$ values of the fabricated electrodes, we can concluded that the electron transfer rates at the PPy/CNFs/CPE was the fastest, indicating the role of the synergic effects of PPy and CNFs to promote electron transfer reaction of $\left[\mathrm{Fe}(\mathrm{CN})_{6}\right]^{3-/ 4-}$. The EIS measurements are in good agreement with those obtained with $\mathrm{CV}$.

Fig. 3 Nyquist plots of bare CPE (red dots), CNFs/CPE (blue dots), PPy/CPE (cyan dots), and $\mathrm{PPy} / \mathrm{CNF} / \mathrm{CPE}$ (green dots) in $10 \mathrm{mM}\left[\mathrm{Fe}(\mathrm{CN})_{6}\right]^{3-/ 4-}$ and $0.5 \mathrm{M} \mathrm{KCl}$ in frequency range from $63 \mathrm{kHz}$ to $10 \mathrm{mHz}$ at an applied potential of $+0.2 \mathrm{~V} / \mathrm{SCE}$. Inset is the simulation results of the EIS spectra

\section{SEM characterization of the prepared electrodes}


The surface morphologies of different modified electrodes was characterized by FEG-SEM as shown in Fig. 4. The bare CPE (Fig. 4a) was characterized by a surface formed by irregularly shaped flakes of graphite isolated from each other with a micrometer-size [50]. CNFs modified CPE (Fig. 4b) displays a uniform dispersion of CNFs on the electrode surface, and forming a spaghetti-like porous reticular formation which can offer a much active surface than in the case of bare CPE [48, 51]. CPE coated with PPy film (Fig. 4c) showed a cauliflower-like morphology with a micrometric grain size, while in the case of PPy film modified CNFs/CPE (Fig. 4d) it could be seen that the PPy was uniformly deposed on the CNFs surface revealing a finer and more compact structure.

Fig. 4 SEM images of a) bare CPE, b) CNFs/CPE, c) PPy/CPE and d) PPy/CNFs/CPE Anodic striping behavior for $\mathrm{Pb}^{2+}$ determination

The analytical performances of the fabricated electrodes were tested using SWASV for the determination of $100 \mu \mathrm{g} \mathrm{L}^{-1} \mathrm{~Pb}^{2+}$ in $0.1 \mathrm{M}$ acetate buffer solution at $\mathrm{pH} 4.5$. Fig. 5 showed the square wave voltammograms (SWVs) recorded at different modified electrodes after a preconcentration time of 180 seconds, and a deposition potential of $-1.2 \mathrm{~V} / \mathrm{SCE}$.

Fig. $5 \mathrm{SWVs}$ of $100 \mu \mathrm{g} \mathrm{L}^{-1} \mathrm{~Pb}^{2+}$ at different modified electrodes. Deposition potential $-1.2 \mathrm{~V}$, deposition time $180 \mathrm{~s}$, frequency $50 \mathrm{~Hz}$, amplitude $50 \mathrm{mV}$, step potential $5 \mathrm{mV}$ and supporting electrolyte $0.1 \mathrm{M}$ acetate buffer $(\mathrm{pH} 4.5)$

An anodic stripping peak was obtained at different modified electrodes, corresponds to the reoxidation of the reduced lead metals $(\mathrm{Pb})$ to lead ions $\left(\mathrm{Pb}^{2+}\right)$. It could be seen that the best response was obtained at $\mathrm{PPy} / \mathrm{CNF} / \mathrm{CPE}$. The peak current of $\mathrm{Pb}^{2+}$ was improved seven times more than in the case of bare $\mathrm{CPE}$. The enhanced stripping currents of $\mathrm{Pb}^{2+}$ at $\mathrm{PPy} / \mathrm{CNFs} / \mathrm{CPE}$ is due to a larger amount of $\mathrm{Pb}^{2+}$ reduced at its surface. Indeed, the PPy/CNFs nanocomposite modified CPE can provide a high active surface area and good electrical conductivity, which 
allows an easier electron transfer between the electrode and the nanocomposite film. In addition, to the ability of PPy film to chelate the metal ions via amino groups along its macromolecular chain as in the case of some others conjugated conducting polymers such as 1,8-diaminonaphthalene, 1,5-diaminonaphthalene and polyaniline $[11,52-54]$. These proprieties make the PPy/CNFs nanocomposite as a perfect sensing material for traces $\mathrm{Pb}^{2+}$ detection. At bare CPE and modified with CNFs we note a slight shift of peak potential of $\mathrm{Pb}^{2+}$ which could be attributed to the adsorption phenomena on their surfaces [46]. The overall mechanism of accumulation and anodic striping of $\mathrm{Pb}^{2+}$ at $\mathrm{PPy} / \mathrm{CNF} / \mathrm{CPE}$ using SWASV could be provided as the fallowing:

Accumulation step:

$(\mathrm{PPy} / \mathrm{CNFs})_{\text {working electrode surface }}+\left(\mathrm{Pb}^{2+}\right)_{\text {solution }}+2 \mathrm{e}^{-} \rightarrow\left(\mathrm{Pb}^{0}-\mathrm{PPy} / \mathrm{CNFs}\right)_{\text {working electrode surface }}$

Anodic stripping step:

$\left(\mathrm{Pb}^{0}-\mathrm{PPy} / \mathrm{CNFs}\right)_{\text {working electrode surface }} \rightarrow\left(\mathrm{Pb}^{2+}\right)_{\text {solution }}+(\mathrm{PPy} / \mathrm{CNFs})_{\text {working electrode surface }}+2 \mathrm{e}$

\section{Optimization of the experimental conditions}

\section{Effect of supporting electrolytes and SWASV conditions}

It is well known that during the stripping analysis of heavy metal ions using SWASV, the peak response is directly proportional to their concentration. Therefore, the optimization of the experimental conditions including supporting electrolytes and SWASV conditions is very important to improve the sensitivity of the method. The effect of supporting electrolytes was studied in different solutions: $0.1 \mathrm{M}$ acetate buffer $\left(\mathrm{CH}_{3} \mathrm{COOH} / \mathrm{CH}_{3} \mathrm{COONa}\right), 0.1 \mathrm{M}$ phosphate buffer $\left(\mathrm{NaH}_{2} \mathrm{PO}_{4} / \mathrm{Na}_{2} \mathrm{HPO}_{4}\right)$, and $0.1 \mathrm{M}$ hydrochloric acid $(\mathrm{HCl})$. The anodic peak currents for the detection of $100 \mu \mathrm{g} \mathrm{L}^{-1} \mathrm{~Pb}^{2+}$ using $\mathrm{PPy} / \mathrm{CNF} / \mathrm{CPE}$ showed that a high current response was obtained in $0.1 \mathrm{M}$ acetate buffer at $\mathrm{pH}$ 4.5. Therefore, it was selected as an appropriate supporting electrolyte for the next experiments. Previous studies showed that the acetate buffer 
was a commonly supporting electrolyte used in anodic stripping voltammetry of $\mathrm{Pb}^{2+}[11,55]$. Then, the SWASV parameters including frequency, step potential, and amplitude were optimized using $\mathrm{PPy} / \mathrm{CNF} / \mathrm{CPE}$ in $0.1 \mathrm{M}$ acetate buffer at $\mathrm{pH} 4.5$ as supporting electrolyte. The analysis of $100 \mu \mathrm{g} \mathrm{L}^{-1} \mathrm{~Pb}^{2+}$ revealed that a high stripping peak current was obtained using simultaneously a frequency of $50 \mathrm{~Hz}$, a step potential of $5 \mathrm{mV}$ and an amplitude of $50 \mathrm{mV}$.

\section{Effect of deposition potential}

The deposition potential is an important parameter in striping analysis, which can strongly affect the sensitivity of the method. The effect of this parameter on the stripping signal of $\mathrm{Pb}^{2+}$ using the modified electrode PPy/CNFs/CPE was investigated in the range of potential from 0.8 to $-1.6 \mathrm{~V} / \mathrm{SCE}$. Fig. 6 shows a plot of stripping peak currents of $150 \mu \mathrm{g} \mathrm{L}^{-1} \mathrm{~Pb}^{2+}$ versus the deposition potential. These results were recorded in $0.1 \mathrm{M}$ acetate buffer $\mathrm{pH} 4.5$ at a deposition time of 180 seconds. The stripping peak currents of $\mathrm{Pb}^{2+}$ were gradually increased when the deposition potential shifted from -0.8 to $-1.3 \mathrm{~V} / \mathrm{SCE}$, a high stripping peak current was obtained at $-1.3 \mathrm{~V} / \mathrm{SCE}$. However, when the deposition potential become more negative the stripping peak currents of $\mathrm{Pb}^{2+}$ were greatly decreased. This behavior is due to the evolution of hydrogen at the electrode surface, which could influence the active surface area leading to a decrease of amount $\mathrm{Pb}^{2+}$ reduced on the electrode surface [51]. Consequently, a potential of $-1.2 \mathrm{~V} / \mathrm{SCE}$ was selected as an optimum deposition potential for the following experiments.

Fig. 6 Effect of deposition potential on the stripping peak current of $150 \mu \mathrm{g} \mathrm{L}^{-1} \mathrm{~Pb}^{2+}$ in $0.1 \mathrm{M}$ acetate buffer $(\mathrm{pH} 4.5)$ at PPy/CNFs/CPE. The SWVs were recorded at frequency of $50 \mathrm{~Hz}$, amplitude of $50 \mathrm{mV}$ and step potential of $5 \mathrm{mV}$

\section{Effect of the preconcentration time}

The influence of the preconcentration time was investigated from 2 to $24 \mathrm{~min}$ in $0.1 \mathrm{M}$ acetate buffer solution $\mathrm{pH} 4.5$ containing $150 \mu \mathrm{g} \mathrm{L}^{-1} \mathrm{~Pb}^{2+}$ at a deposition potential of $-1.2 \mathrm{~V} / \mathrm{SCE}$. Fig. 
7 shows a plot of peak currents of $\mathrm{Pb}^{2+}$ versus the preconcentration time. The stripping peak currents of $\mathrm{Pb}^{2+}$ are almost linear with the increase of the preconcentration time between 2 to $18 \mathrm{~min}$, which is attributed to the increase of amount $\mathrm{Pb}^{2+}$ reduced on the electrode surface. These results clearly demonstrate that the PPy/CNFs nanocomposite is characterized with a high capacity to the accumulation the reduced metal ions due to its large active surface area. At a preconcentration time greater than $18 \mathrm{~min}$, the electrode surface begins to saturate. It is known that a long preconcentration time can improve the sensitivity of the method and also decrease the detection limit, because of rapid saturation of the electrode surface, then a preconcentration time of $10 \mathrm{~min}$ is therefore selected as a compromise between a high signal and a suitable time for the next experiments.

Fig. 7 Effect of deposition time on the stripping peak current of $150 \mu \mathrm{g} \mathrm{L}^{-1} \mathrm{~Pb}^{2+}$ in $0.1 \mathrm{M}$ acetate buffer ( $\mathrm{pH}$ 4.5) using PPy/CNFs/CPE at deposition potential of -1.2. Other experimental conditions are mentioned in Fig. 7

\section{Analytical characteristics}

Under the optimized experimental conditions described above, the calibration curves for determination of $\mathrm{Pb}^{2+}$ at different concentration range from 0.2 to $130 \mu \mathrm{g} \mathrm{L}^{-1}$ using PPy/CNFs/CPE are illustrated in Fig. 8.

Fig. 8 Calibration curve for $\mathrm{Pb}^{2+}$ determination, from down to up: $0.2,0.5,1,5,15,20,30,40$, 60, 80, 100, and $130 \mu \mathrm{g} \mathrm{L}^{-1} \mathrm{~Pb}^{2+}$ in $0.1 \mathrm{M}$ acetate buffer ( $\left.\mathrm{pH} 4.5\right)$ at PPy/CNFs/CPE under the optimized experimental conditions. Insert the calibration plot of oxidation peak current versus different concentrations of $\mathrm{Pb}^{2+}$

It could be seen that the stripping peak currents $\left(i_{p}\right)$ increase linearly with the concentration of $\mathrm{Pb}^{2+}(C)$, the calculated correlation equation is: $i_{p}=0.289 C-0.0556\left(\mathrm{R}^{2}=0.9904\right)$. The limit of detection (LOD) is calculated using the following equation: $L O D=3 \sigma / b$, where $\sigma$ is the 
standard deviation of the response, according to the IUPAC recommendations $\sigma$ is the mean value for 10 voltammograms of the blank, and $b$ is the slope of the calibration curve [56]. Therefore, the $\mathrm{LOD}$ of $\mathrm{Pb}^{2+}$ determination is found to be $0.05 \mu \mathrm{g} \mathrm{\textrm {L } ^ { - 1 }}$. The analytical performances of the proposed method are compared with other methods previously reported in the literature for $\mathrm{Pb}^{2+}$ determination are given in Table 1 .

Table 1 Comparison of the analytical performance of PPy/CNFs/CPE with some other modified electrode for $\mathrm{Pb}^{2+}$ determination in aqueous media (detection limit and linear range are given in $\mu \mathrm{g} \mathrm{L}^{-1}$ except $*$ in $\mathrm{nM}$ and ${ }^{\$}$ in $\mu \mathrm{M}$ )

The repeatability of the proposed method using PPy/CNFs/CPE under the optimized

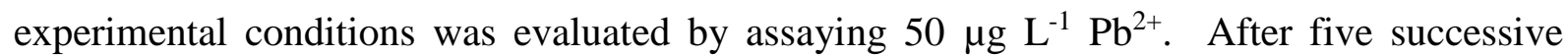
measurements using the same modified electrode, the calculated relative standard deviation (RSD) was around $2.3 \%$. On the other hand, the reproducibility of the proposed method was also tested, a series of five electrodes were prepared and then applied for the detection of $50 \mu \mathrm{g}$ $\mathrm{L}^{-1} \mathrm{~Pb}^{2+}$. The RSD of the measurements for the prepared five electrodes was equal to $3.1 \%$, which indicated that a very satisfactory reproducibility was obtained.

\section{Interference study}

The anodic stripping analysis of $\mathrm{Pb}^{2+}$ could be affected by the interferences from other heavy metal ions. In this work, three metal ions including $\mathrm{Cd}^{2+}, \mathrm{Cu}^{2+}$ and $\mathrm{Hg}^{2+}$ are selected as interfering ions to investigate the selectivity of the proposed method. Indeed, during the preconcentration of $\mathrm{Cd}^{2+}$ and $\mathrm{Cu}^{2+}$ these metal ions can occupy available deposition and/or

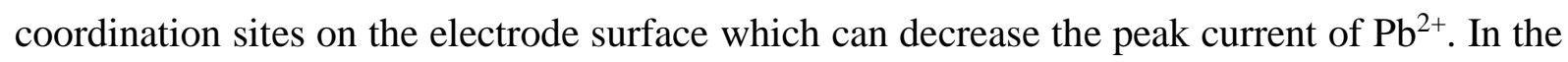
case of $\mathrm{Hg}^{2+}$, the stripping peak current of $\mathrm{Pb}^{2+}$ can be affected by the formation of mercury film at the electrode surface, which can cause an easy reduction of $\mathrm{Pb}^{2+}$ and leading to a high peak current of $\mathrm{Pb}^{2+}$ due to the formation of an amalgam of $\mathrm{Pb}-\mathrm{Hg}$ at the electrode surface. Fig. 
9 shows the SWVs obtained using PPy/CNFs/CPE for the analysis of $50 \mu \mathrm{g} \mathrm{L}^{-1} \mathrm{~Pb}^{2+}$ in the

absence and presence of different concentration metals ions interferents. It can be seen that the peak current of $\mathrm{Pb}^{2+}$ is almost constant in the presence of metals ions interferents, except in the case of the presence of $\mathrm{Hg}^{2+}$ a slight shift of peak potential of $\mathrm{Pb}^{2+}$ is observed. This marginal change of potential might be attributed to the formation of intermetallic compounds of $\mathrm{Pb}-\mathrm{Hg}$ as reported in previous study $[15,60]$. The obtained results clearly demonstrate that the selective detection of $\mathrm{Pb}^{2+}$ using $\mathrm{PPy} / \mathrm{CNF} / \mathrm{CPE}$ under the optimized experimental conditions is not affected by the presence of metal ions interferents $\mathrm{Cd}^{2+}, \mathrm{Cu}^{2+}$, and $\mathrm{Hg}^{2+}$.

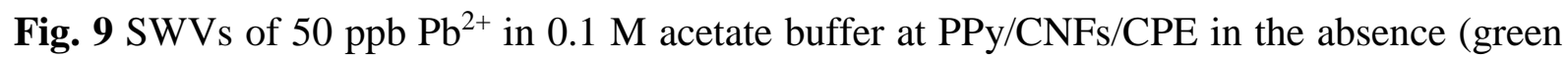
line) and presence of interferents: $100 \mu \mathrm{g} \mathrm{L}^{-1}$ of $\mathrm{Cd}^{2+}$ (red line), and $50 \mu \mathrm{g} \mathrm{L}^{-1} \mathrm{Cd}^{2+}, 150 \mu \mathrm{g} \mathrm{L}-1$ of $\mathrm{Cu}^{2+}$ and $\mathrm{Hg}^{2+}$ for each one (blue line)

\section{Analytical application}

The effectiveness application of this method to analysis $\mathrm{Pb}^{2+}$ ions in real samples was also tested by analyzing a tap water of our laboratory. For that, three samples of tap water were prepared. Briefly, an appropriate amount of acetic acid and sodium acetate were added to the water simples to obtain a concentration of $0.1 \mathrm{M}$ for each compound, the $\mathrm{pH}$ was adjusted at 4.5. Then, the prepared samples were analyzed using the modified electrode PPy/CNFs/CPE under the optimized experimental conditions. The results showed the absence of obvious responses to $\mathrm{Pb}^{2+}$, indicating that the concentration of $\mathrm{Pb}^{2+}$ in the analyzed samples was extremely low. In this case, the standard addition method was used, the three prepared samples were spiked with different concentrations of $\mathrm{Pb}^{2+}$ for recovery evaluation. As can be seen in Table 2, the recoveries are varied from $97.6 \%$ to $102 \%$, indicating that the proposed method can be efficiently applied to $\mathrm{Pb}^{2+}$ detection in water real samples. 
Table 2 Recovery and relative standard deviation (RSD) of $\mathrm{Pb}^{2+}$ in the tap water samples using the modified electrode PPy/CNFs/CPE $(\mathrm{n}=3)\left({ }^{*}\right.$ Not detected $)$ 


\section{Conclusion}

In this work, a new nanocomposite of CNMs/CPs modified CPE was fabricated by combining the unique properties of polypyrrole and carbon nanofibers. The obtained nanocomposite provided excellent electrical conductivity and a high active surface area compared to the bare CPE as confirmed by CV and EIS measurements. Using SWASV and under the optimized experimental conditions, the modified electrode PPy/CNFs/CPE showed good analytical performances towards $\mathrm{Pb}^{2+}$ determination, with a very low detection limit, a satisfactory selectivity, an acceptable repeatability and reproducibility. Moreover, the proposed method was applied to the determination of $\mathrm{Pb}^{2+}$ in real water sample with satisfactory results, and also offers the possibility of simultaneously detection of several heavy metals ions $\mathrm{Pb}^{2+}, \mathrm{Cu}^{2+}, \mathrm{Cd}^{2+}$, and $\mathrm{Hg}^{2+}$. 


\section{Acknowledgements}

This work was supported by MESRSFC (Ministère de l'Enseignement Supérieur et de la Recherche Scientifique et de la Formation des cadres - Morocco) and CNRST (Centre National pour la Recherche Scientifique et Technique - Morocco) (Project number PPR/2015/72). The authors also acknowledge Mrs. Françoise Pillier for FEG-SEM analysis, and the Erasmus Mundus program EMMAG. 


\section{References}

1. Moniruzzaman M, Winey KI (2006) Polymer Nanocomposites Containing Carbon Nanotubes. Macromolecules 39:5194-5205.

2. Tang C, Chen N, Hu X (2017) Conducting Polymer Nanocomposites: Recent Developments and Future Prospects. 1-44.

3. Kaur N, Thakur H, Prabhakar N (2016) Conducting polymer and multi-walled carbon nanotubes nanocomposites based amperometric biosensor for detection of organophosphate. J Electroanal Chem 775:121-128.

4. Zuo Y, Xu J, Zhu X, Duan X, Lu L, Gao Y, Xing H, Yang T, Ye G, Yu Y (2016) Poly(3,4ethylenedioxythiophene) nanorods/graphene oxide nanocomposite as a new electrode material for the selective electrochemical detection of mercury (II). Synth Met 220:1419.

5. Mason LH, Harp JP, Han DY (2014) Pb Neurotoxicity: Neuropsychological Effects of Lead Toxicity. BioMed Res Int 2014:e840547.

6. Flora G, Gupta D, Tiwari A (2012) Toxicity of lead: a review with recent updates.

7. Zhou Q, Lin Y, Lin Y, Wei Q, Chen G, Tang D (2016) Highly sensitive electrochemical sensing platform for lead ion based on synergetic catalysis of DNAzyme and $\mathrm{Au}-\mathrm{Pd}$ porous bimetallic nanostructures. Biosens Bioelectron 78:236-243.

8. Intarakamhang S, Schuhmann W, Schulte A (2013) Robotic heavy metal anodic stripping voltammetry: ease and efficacy for trace lead and cadmium electroanalysis. J Solid State Electrochem 17:1535-1542.

9. Wang J (2006) Analytical electrochemistry. John Wiley \& Sons

10. Wang Z, Li L, Liu E (2013) Graphene ultrathin film electrodes modified with bismuth nanoparticles and polyaniline porous layers for detection of lead and cadmium ions in acetate buffer solutions. Thin Solid Films 544:362-367.

11. Vu HD, Nguyen L-H, Nguyen TD, Nguyen HB, Nguyen TL, Tran DL (2014) Anodic stripping voltammetric determination of $\mathrm{Cd} 2+$ and $\mathrm{Pb} 2+$ using interpenetrated MWCNT/P1,5-DAN as an enhanced sensing interface. Ionics 21:571-578.

12. Nguyen TD, Dang TTH, Thai H, Nguyen LH, Tran DL, Piro B, Pham MC (2016) Onestep Electrosynthesis of Poly(1,5-diaminonaphthalene)/Graphene Nanocomposite as Platform for Lead Detection in Water. Electroanalysis 28:1907-1913.

13. Wei Y, Yang R, Liu J-H, Huang X-J (2013) Selective detection toward $\mathrm{Hg}$ (II) and $\mathrm{Pb}$ (II) using polypyrrole/carbonaceous nanospheres modified screen-printed electrode. Electrochimica Acta 105:218-223.

14. Zhao Z-Q, Chen X, Yang Q, Liu J-H, Huang X-J (2012) Selective adsorption toward toxic metal ions results in selective response: electrochemical studies on a polypyrrole/reduced graphene oxide nanocomposite. Chem Commun 48:2180-2182. 
15. Seenivasan R, Chang W-J, Gunasekaran S (2015) Highly Sensitive Detection and Removal of Lead Ions in Water Using Cysteine-Functionalized Graphene Oxide/Polypyrrole Nanocomposite Film Electrode. ACS Appl Mater Interfaces 7:1593515943.

16. Salmanipour A, Taher MA (2011) An electrochemical sensor for stripping analysis of $\mathrm{Pb}$ (II) based on multiwalled carbon nanotube functionalized with 5-Br-PADAP. J Solid State Electrochem 15:2695-2702.

17. Švancara I, Vytřas K, Kalcher K, Walcarius A, Wang J (2009) Carbon Paste Electrodes in Facts, Numbers, and Notes: A Review on the Occasion of the 50-Years Jubilee of Carbon Paste in Electrochemistry and Electroanalysis. Electroanalysis 21:7-28.

18. Kisan Koirala, Jose H. Santos, Ai Ling Tan, Mohammad A. Ali, Aminul H. Mirza (2016) Chemically modified carbon paste electrode for the detection of lead, cadmium and zinc ions. Sens Rev 36:339-346.

19. Raghu GK, Sampath S, Pandurangappa M (2012) Chemically functionalized glassy carbon spheres: a new covalent bulk modified composite electrode for the simultaneous determination of lead and cadmium. J Solid State Electrochem 16:1953-1963.

20. Morales GR, Silva TR, Galicia L (2003) Carbon paste electrodes electrochemically modified with cyclodextrins. J Solid State Electrochem 7:355-360.

21. Morante-Zarcero S, Pérez-Quintanilla D, Sierra I (2015) A disposable electrochemical sensor based on bifunctional periodic mesoporous organosilica for the determination of lead in drinking waters. J Solid State Electrochem 19:2117-2127.

22. D'Souza OJ, Mascarenhas RJ, Satpati AK, Detriche S, Mekhalif Z, Delhalle J, A D (2017) High electrocatalytic oxidation of folic acid at carbon paste electrode bulk modified with iron nanoparticle-decorated multiwalled carbon nanotubes and its application in food and pharmaceutical analysis. Ionics 23:201-212.

23. Afkhami A, Bagheri H, Khoshsafar H, Saber-Tehrani M, Tabatabaee M, Shirzadmehr A (2012) Simultaneous trace-levels determination of $\mathrm{Hg}$ (II) and $\mathrm{Pb}$ (II) ions in various samples using a modified carbon paste electrode based on multi-walled carbon nanotubes and a new synthesized Schiff base. Anal Chim Acta 746:98-106.

24. Afkhami A, Soltani-Shahrivar M, Ghaedi H, Madrakian T (2016) Construction of Modified Carbon Paste Electrode for Highly Sensitive Simultaneous Electrochemical Determination of Trace Amounts of Copper (II) and Cadmium (II). Electroanalysis 28:296-303.

25. Raoof JB, Ojani R, Kolbadinezhad M (2009) Voltammetric sensor for glutathione determination based on ferrocene-modified carbon paste electrode. J Solid State Electrochem 13:1411.

26. Arvand M, Vaziri M, Zanjanchi MA (2012) Electrochemical behavior and differential pulse voltammetric detection of thiobencarb on 2-(4-((4ethoxyphenyl)diazenyl)phenylamino)ethanol-modified carbon paste electrode. J Solid State Electrochem 16:1151-1159. 
27. Stozhko NY, Malakhova NA, Fyodorov MV, Brainina KZ (2008) Modified carboncontaining electrodes in stripping voltammetry of metals. J Solid State Electrochem 12:1185-1204.

28. JONG KPD, GEUS JW (2000) Carbon Nanofibers: Catalytic Synthesis and Applications. Catal Rev 42:481-510.

29. Kang I, Heung YY, Kim JH, Lee JW, Gollapudi R, Subramaniam S, Narasimhadevara S, Hurd D, Kirikera GR, Shanov V, Schulz MJ, Shi D, Boerio J, Mall S, Ruggles-Wren M (2006) Introduction to carbon nanotube and nanofiber smart materials. Compos Part B Eng 37:382-394.

30. Al-Saleh MH, Sundararaj U (2009) A review of vapor grown carbon nanofiber/polymer conductive composites. Carbon 47:2-22.

31. Lai C-C, Lo C-T (2015) Preparation of Nanostructural Carbon Nanofibers and Their Electrochemical Performance for Supercapacitors. Electrochimica Acta 183:85-93.

32. Wan Y, Yang Z, Xiong G, Guo R, Liu Z, Luo H (2015) Anchoring Fe3O4 nanoparticles on three-dimensional carbon nanofibers toward flexible high-performance anodes for lithium-ion batteries. J Power Sources 294:414-419.

33. Li M, Wu X, Zeng J, Hou Z, Liao S (2015) Heteroatom Doped Carbon Nanofibers Synthesized by Chemical Vapor Deposition as Platinum Electrocatalyst Supports for Polymer Electrolyte Membrane Fuel Cells. Electrochimica Acta 182:351-360.

34. Sun M, Xie Z, Wu X, Deng X, Liu C, Huang Q, Huang B (2017) The synthesis and electrocatalytic activity for ORR of the structured electrode material: CP/Fe-N-CNFs. J Solid State Electrochem 1-12.

35. Li Y, Zhang X, Luo J, Huang W, Cheng J, Luo Z, Li T, Liu F, Guoliang Xu, Ke X, Li L, Geise HJ (2004) Purification of CVD synthesized single-wall carbon nanotubes by different acid oxidation treatments. Nanotechnology 15:1645.

36. Hacker V, Wallnöfer E, Baumgartner W, Schaffer T, Besenhard JO, Schröttner H, Schmied M (2005) Carbon nanofiber-based active layers for fuel cell cathodes preparation and characterization. Electrochem Commun 7:377-382.

37. Ebbesen TW (1996) Wetting, filling and decorating carbon nanotubes. J Phys Chem Solids 57:951-955.

38. Salih FE, Ouarzane A, El Rhazi M Electrochemical detection of lead (II) at bismuth/Poly(1,8-diaminonaphthalene) modified carbon paste electrode. Arab J Chem.

39. Baytak AK, Duzmen S, Teker T, Aslanoglu M (2017) Voltammetric determination of methylparaben and its DNA interaction using a novel platform based on carbon nanofibers and cobalt-nickel-palladium nanoparticles. Sens Actuators B Chem 239:330-337.

40. Baytak AK, Teker T, Duzmen S, Aslanoglu M (2017) A novel electrochemical platform based on carbon nanofibers and tri-metallic nanoparticles of gold, nickel and cobalt for the quantification of ethyl paraben. Mater Sci Eng C 72:301-307. 
41. Dabaghian Z, Rahimpour A (2015) Carboxylated carbon nanofibers as hydrophilic porous material to modification of cellulosic membranes for forward osmosis desalination. Chem Eng Res Des 104:647-657.

42. El-Deen AG, Barakat NAM, Khalil KA, Kim HY (2013) Hollow carbon nanofibers as an effective electrode for brackish water desalination using the capacitive deionization process. New J Chem 38:198-205.

43. Sankal S, Kaynak C (2013) Using various techniques to characterize oxidative functionalized and aminosilanized carbon nanotubes for polyamide matrix. J Reinf Plast Compos 32:75-86.

44. Shi C, Zhitomirsky I (2011) Electrodeposition of composite polypyrrole-carbon nanotube films. Surf Eng 27:655-661.

45. Chen GZ, Shaffer MSP, Coleby D, Dixon G, Zhou W, Fray DJ, Windle AH (2000) Carbon Nanotube and Polypyrrole Composites: Coating and Doping. Adv Mater 12:522-526.

46. Zhao D, Wang T, Han D, Rusinek C, Steckl AJ, Heineman WR (2015) Electrospun Carbon Nanofiber Modified Electrodes for Stripping Voltammetry. Anal Chem 87:93159321.

47. Zhang Y-M, Duan C-Q, Gao A-N (2013) Electrochemical behavior of labetalol at an ionic liquid modified carbon paste electrode and its electrochemical determination. J Serbian Chem Soc 78:281-294.

48. Wu L, Zhang X, Ju H (2007) Detection of NADH and Ethanol Based on Catalytic Activity of Soluble Carbon Nanofiber with Low Overpotential. Anal Chem 79:453-458.

49. Kan X, Zhou H, Li C, Zhu A, Xing Z, Zhao Z (2012) Imprinted electrochemical sensor for dopamine recognition and determination based on a carbon nanotube/polypyrrole film. Electrochimica Acta 63:69-75.

50. Valentini F, Orlanducci S, Terranova ML, Amine A, Palleschi G (2004) Carbon nanotubes as electrode materials for the assembling of new electrochemical biosensors. Sens Actuators B Chem 100:117-125.

51. Zhao D, Wang T, Han D, Rusinek C, Steckl AJ, Heineman WR (2015) Electrospun Carbon Nanofiber Modified Electrodes for Stripping Voltammetry. Anal Chem 87:93159321.

52. El Rhazi M, Majid S (2014) Electrochemical sensors based on polydiaminonaphthalene and polyphenylenediamine for monitoring metal pollutants. Trends Environ Anal Chem $2: 33-42$.

53. Majid S, Rhazi ME, Amine A, Curulli A, Palleschi G (2003) Carbon Paste Electrode BulkModified with the Conducting Polymer Poly(1,8-Diaminonaphthalene): Application to Lead Determination. Microchim Acta 143:195-204.

54. Wang Z, Liu E, Gu D, Wang Y (2011) Glassy carbon electrode coated with polyanilinefunctionalized carbon nanotubes for detection of trace lead in acetate solution. Thin Solid Films 519:5280-5284. 
55. Li H, Li J, Yang Z, Xu Q, Hou C, Peng J, Hu X (2011) Simultaneous determination of ultratrace lead and cadmium by square wave stripping voltammetry with in situ depositing bismuth at Nafion-medical stone doped disposable electrode. J Hazard Mater 191:26-31.

56. Committee AM (1987) Recommendations for the definition, estimation and use of the detection limit. Analyst 112:199-204.

57. Chen L, Li Z, Meng Y, Zhang P, Su Z, Liu Y, Huang Y, Zhou Y, Xie Q, Yao S (2014) Sensitive square wave anodic stripping voltammetric determination of $\mathrm{Cd} 2+$ and $\mathrm{Pb} 2+$ ions at $\mathrm{Bi} / \mathrm{Nafion} /$ overoxidized 2-mercaptoethanesulfonate-tethered polypyrrole/glassy carbon electrode. Sens Actuators B Chem 191:94-101.

58. Zhu L, Xu L, Huang B, Jia N, Tan L, Yao S (2014) Simultaneous determination of Cd(II) and $\mathrm{Pb}$ (II) using square wave anodic stripping voltammetry at a gold nanoparticlegraphene-cysteine composite modified bismuth film electrode. Electrochimica Acta 115:471-477.

59. Wang ZM, Guo HW, Liu E, Yang GC, Khun NW (2010) Bismuth/Polyaniline/Glassy Carbon Electrodes Prepared with Different Protocols for Stripping Voltammetric Determination of Trace $\mathrm{Cd}$ and $\mathrm{Pb}$ in Solutions Having Surfactants. Electroanalysis 22:209-215.

60. Wei Y, Gao C, Meng F-L, Li H-H, Wang L, Liu J-H, Huang X-J (2012) SnO2/Reduced Graphene Oxide Nanocomposite for the Simultaneous Electrochemical Detection of Cadmium(II), Lead(II), Copper(II), and Mercury(II): An Interesting Favorable Mutual Interference. J Phys Chem C 116:1034-1041. 


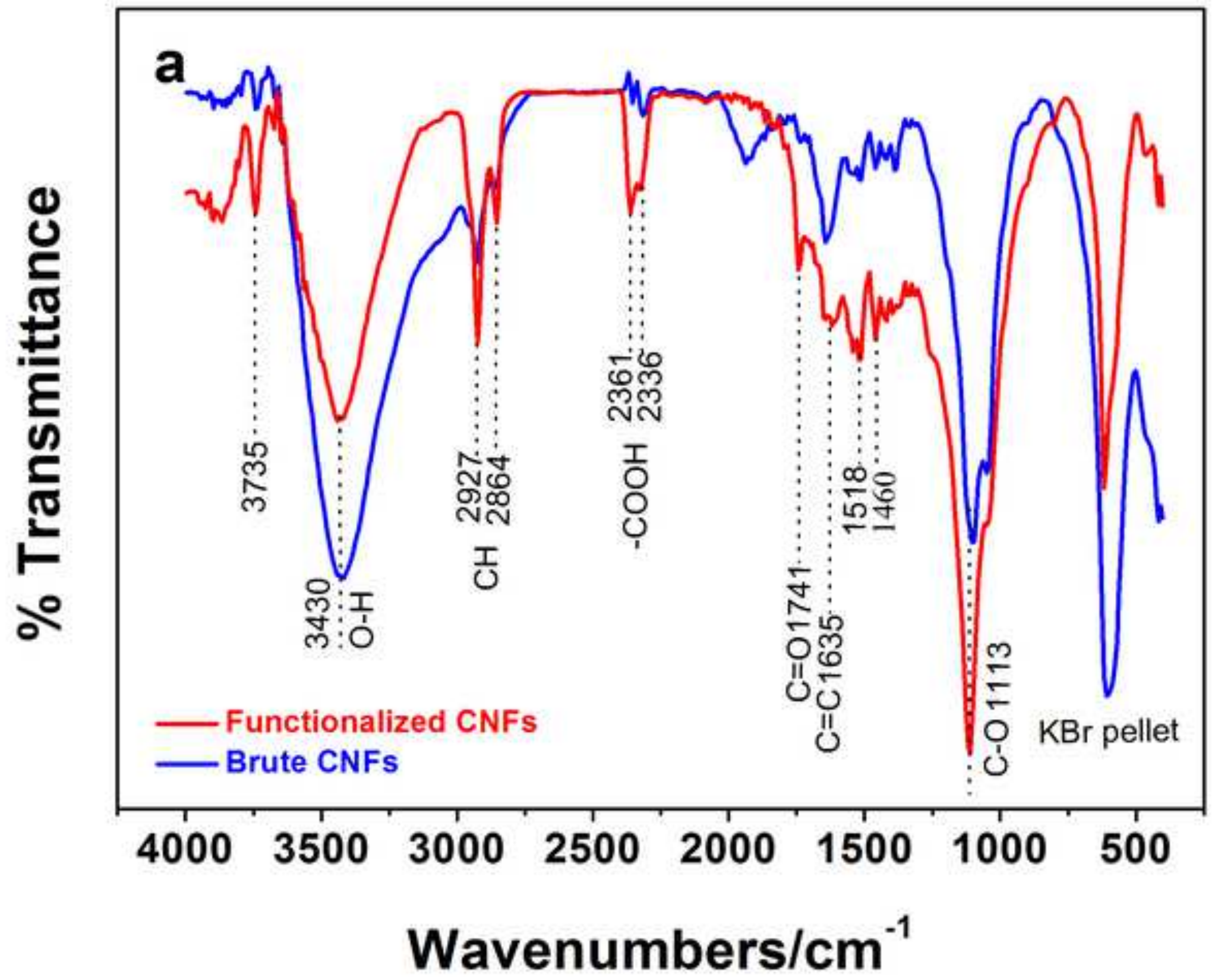




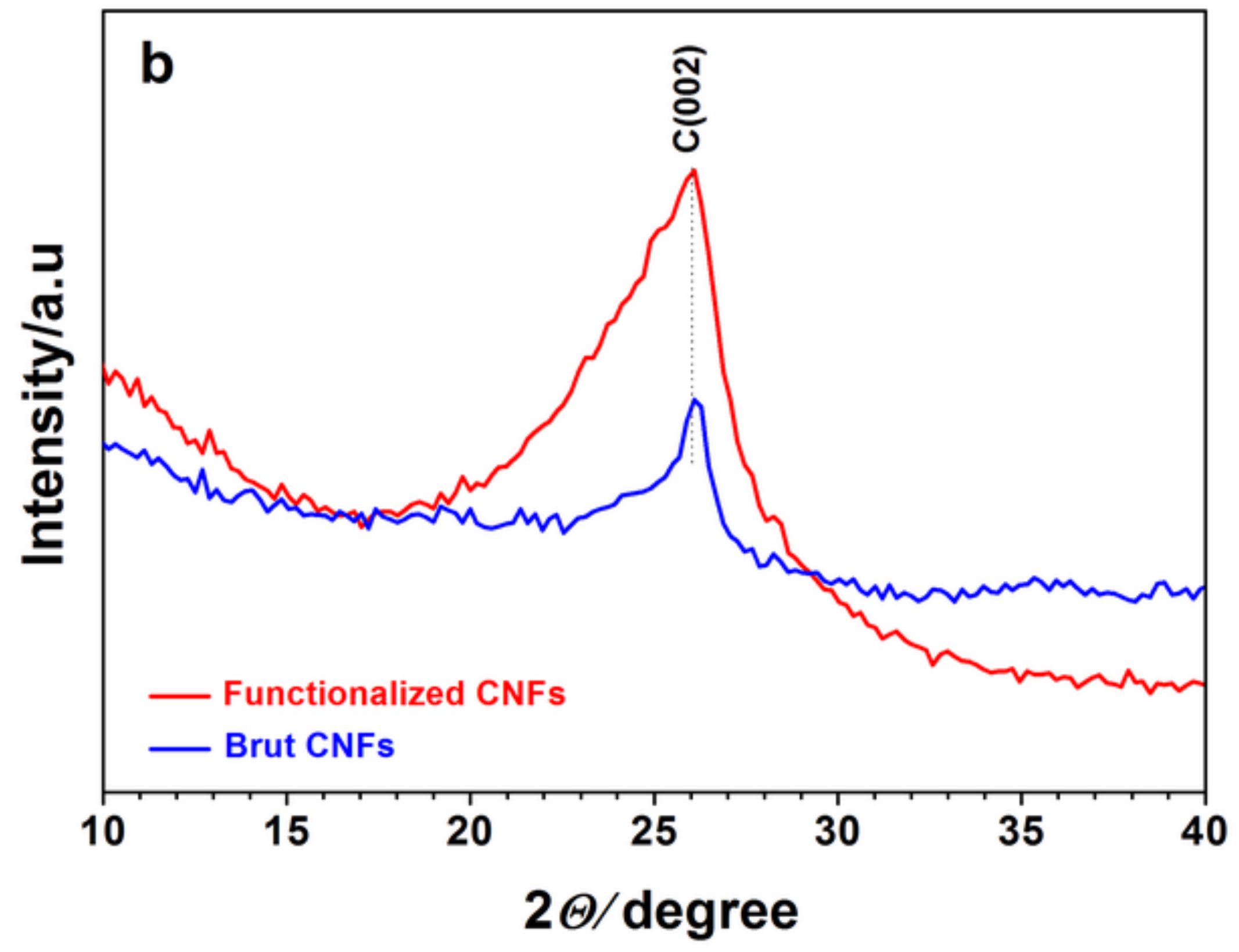




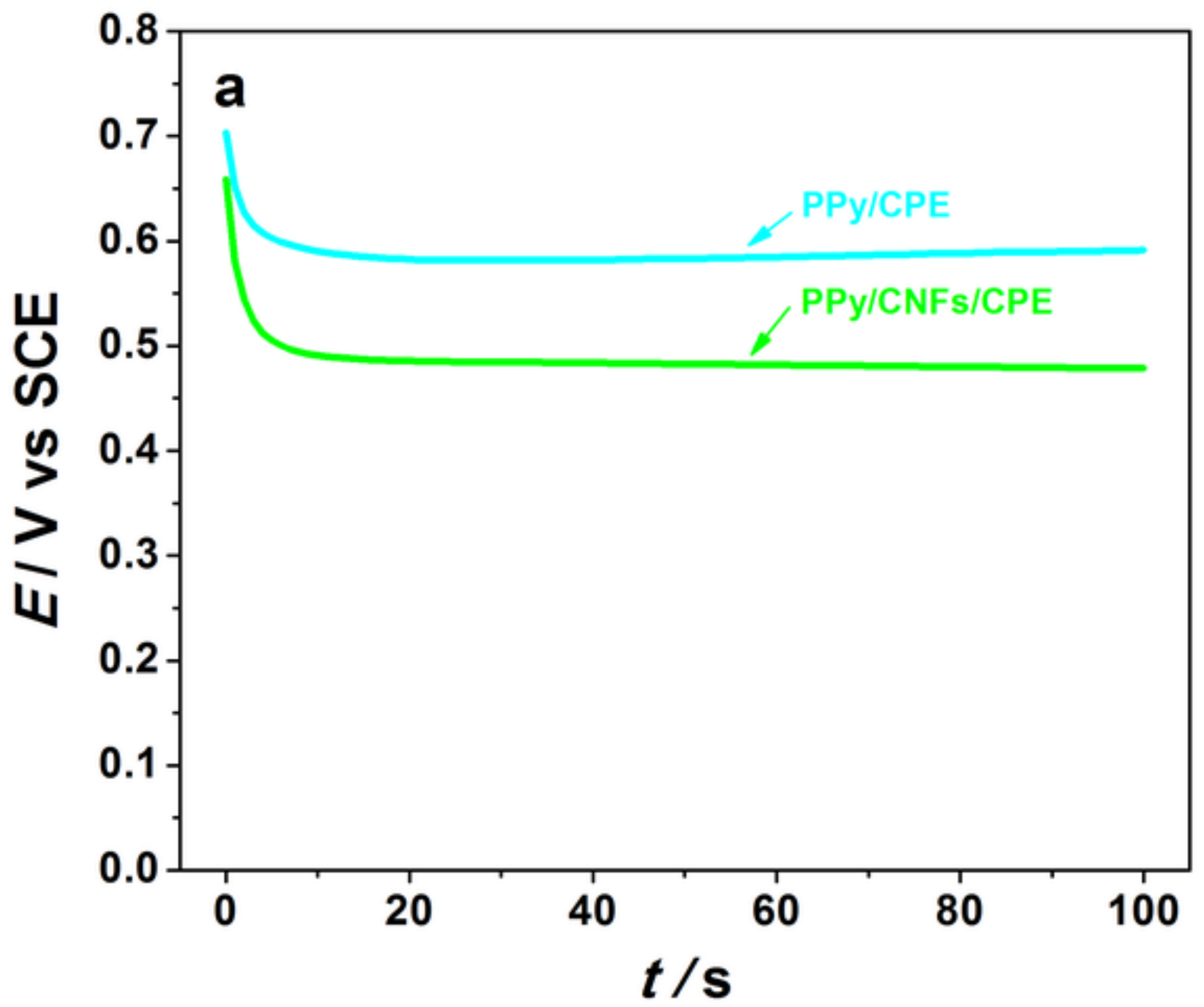




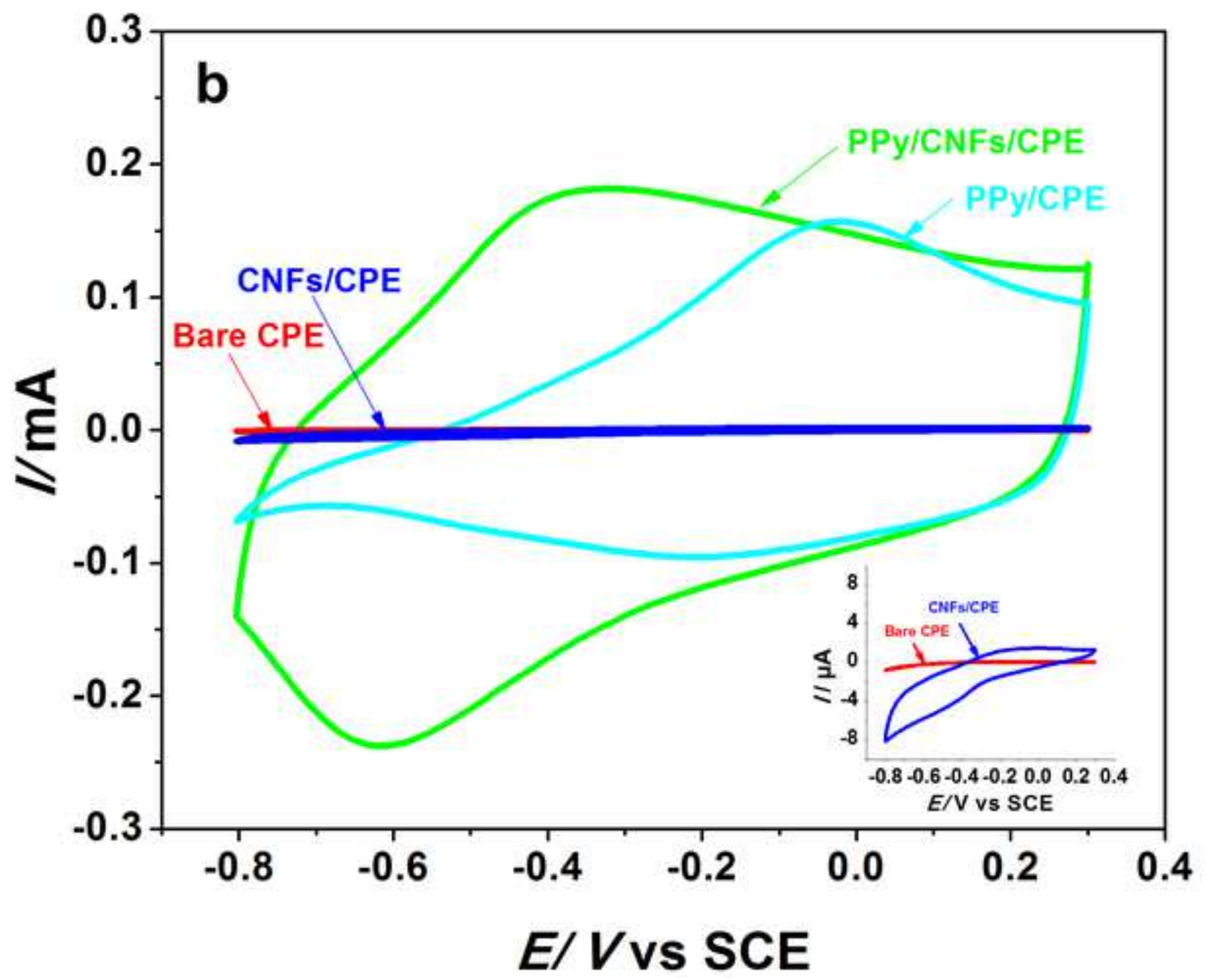




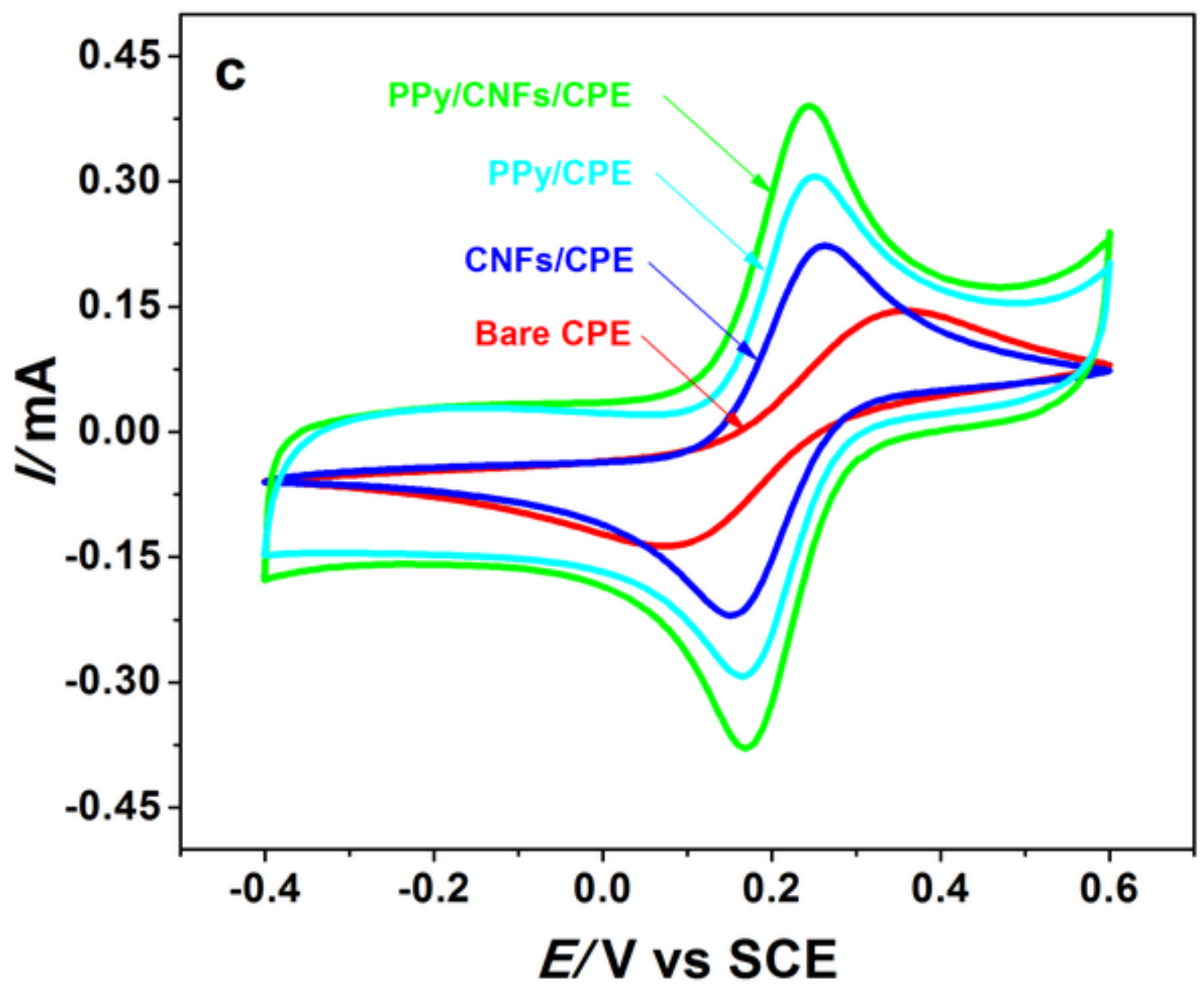




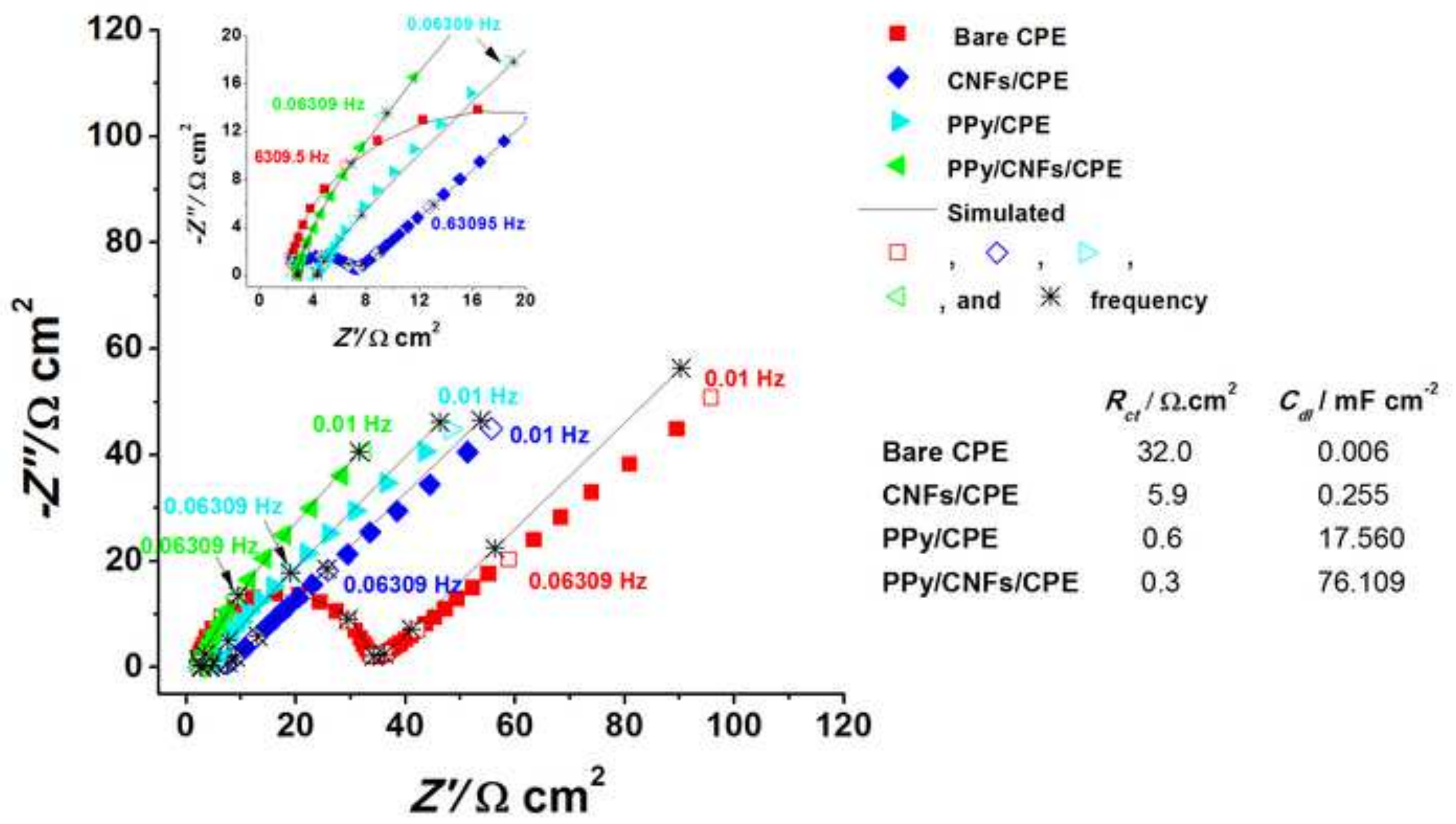




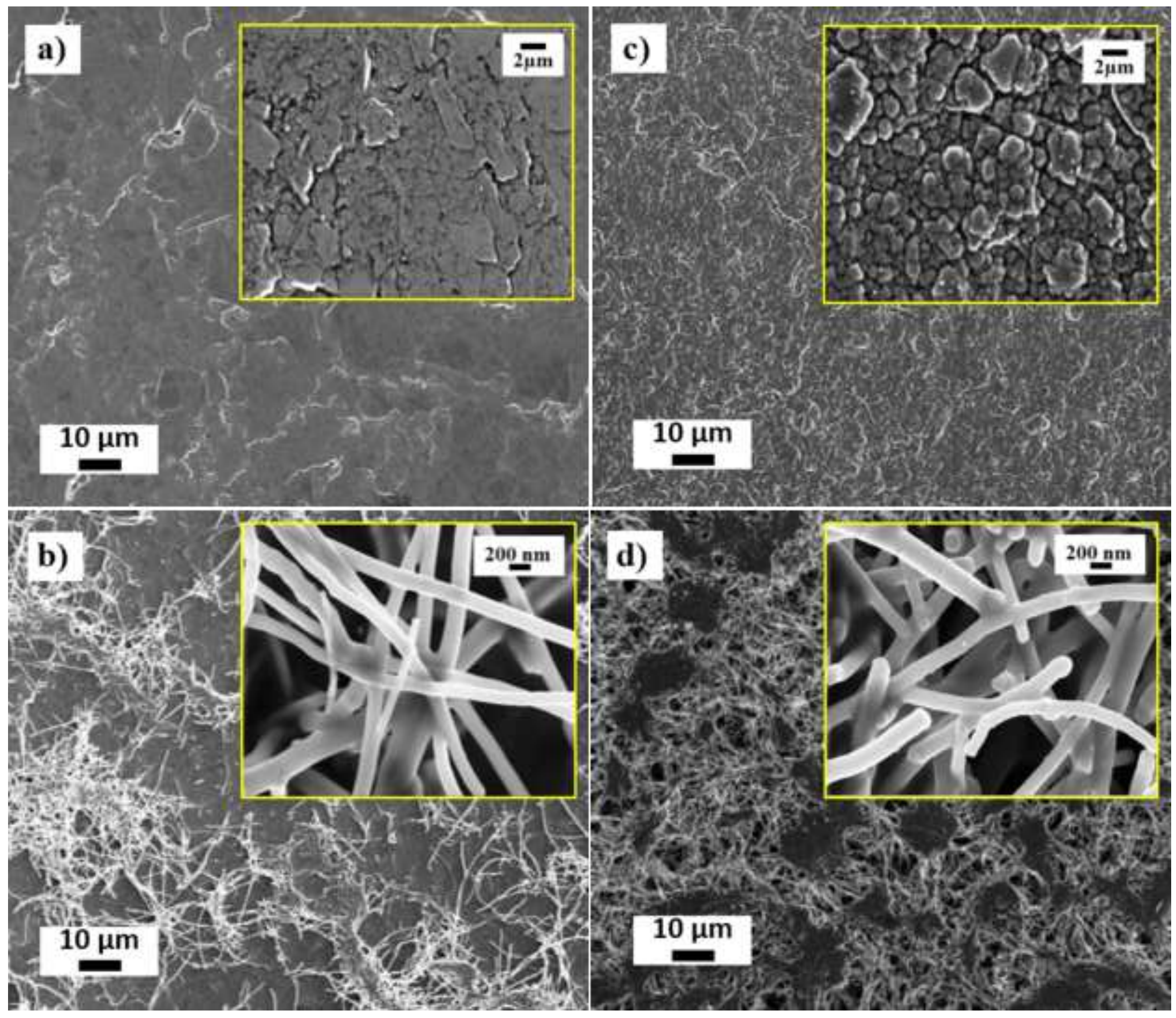




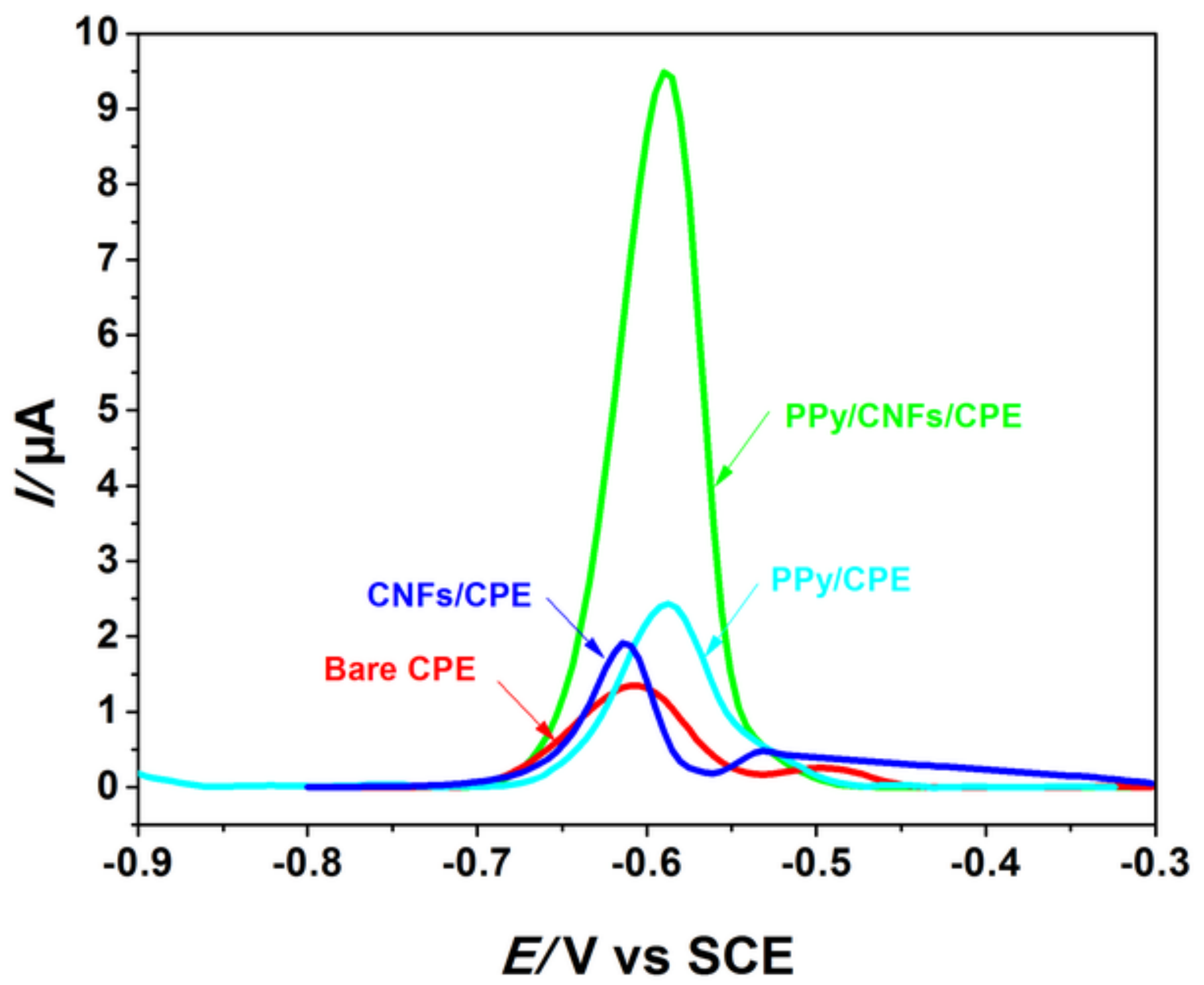




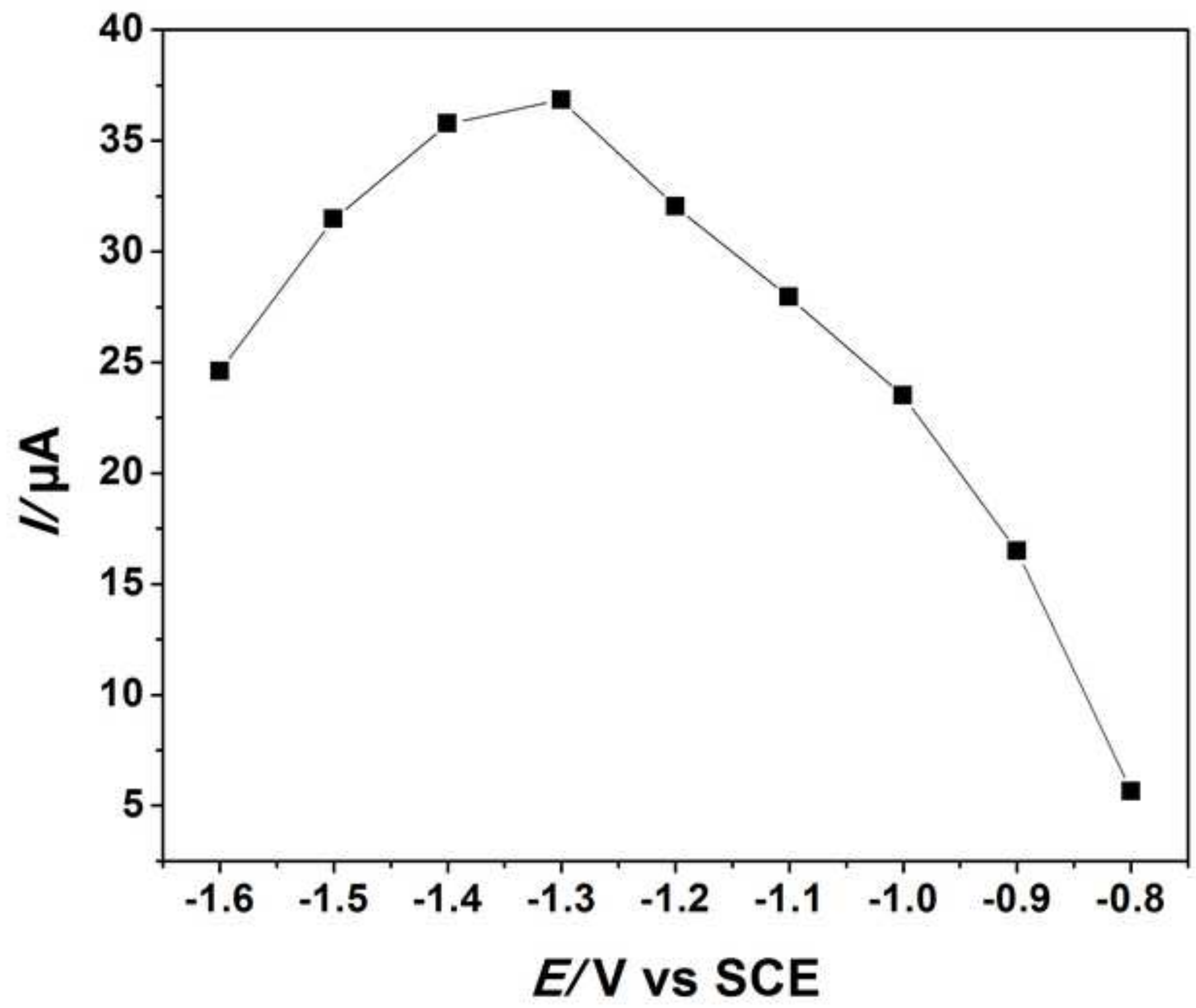




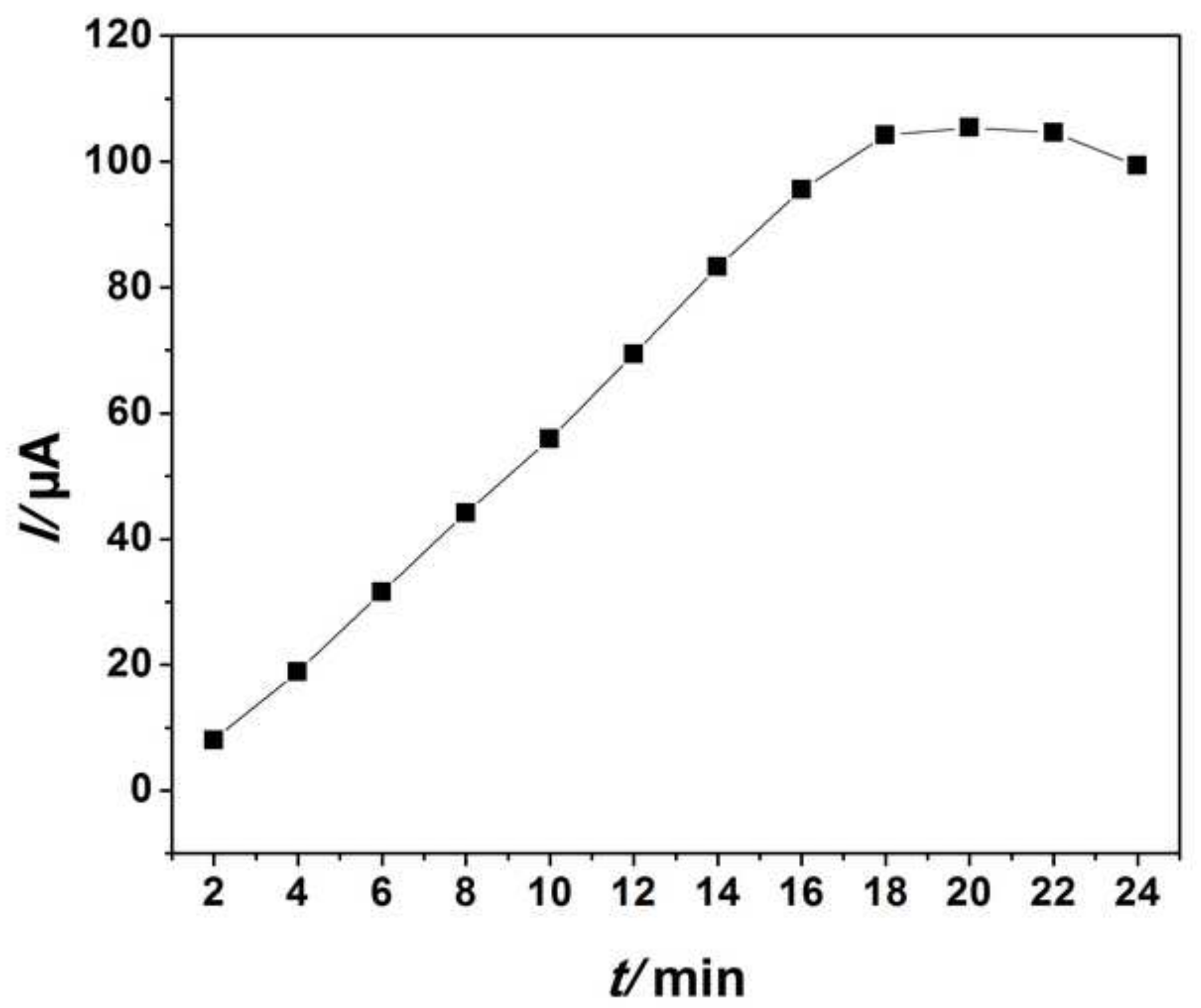




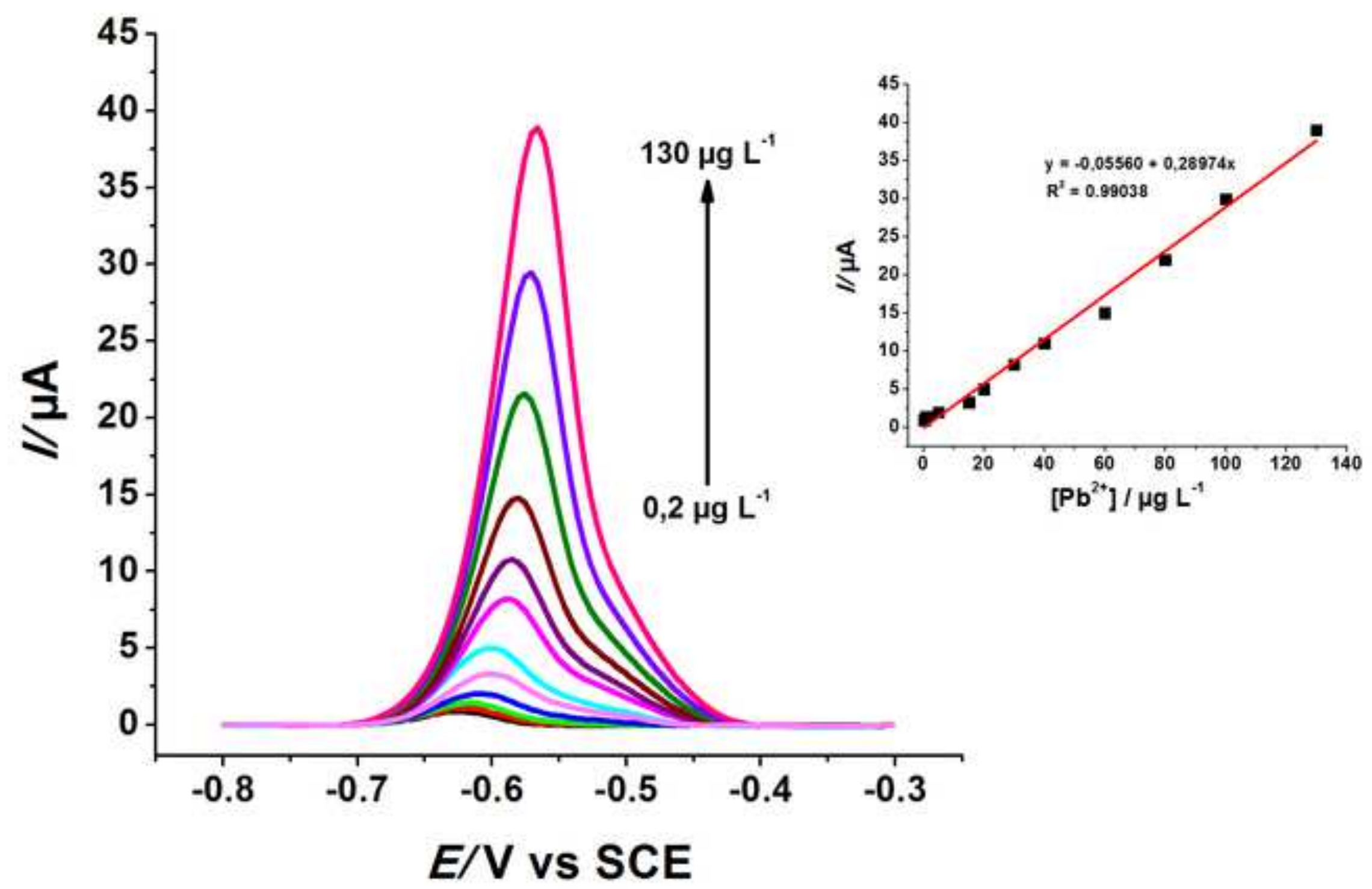




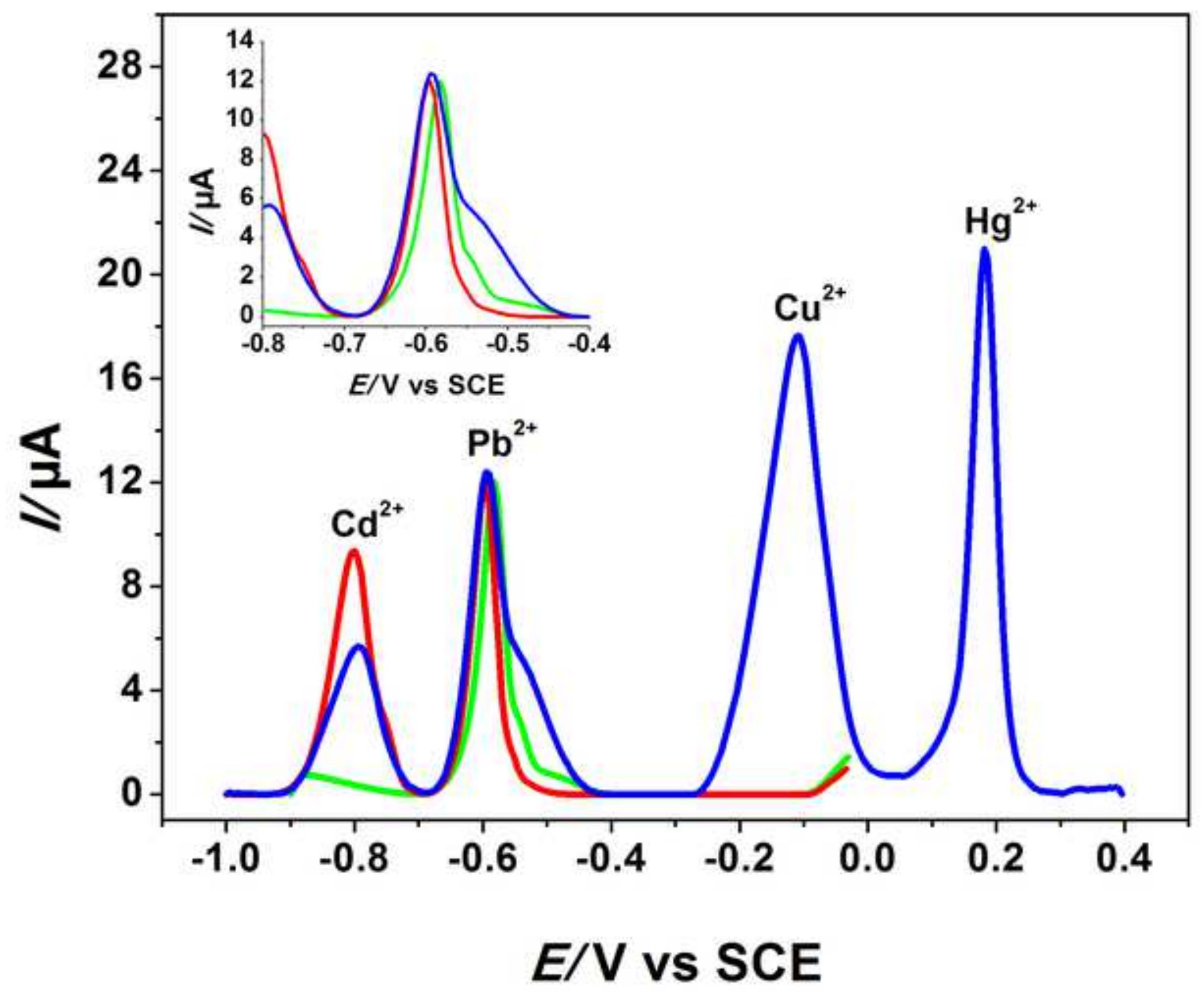


Table 1 Comparison of the analytical performance of PPy/CNFs/CPE with some other modified electrode for $\mathrm{Pb}^{2+}$ determination in aqueous media (detection limit and linear range are given in $\mu \mathrm{g} \mathrm{L}^{-1}$ except $*$ in $\mathrm{nM}$ and ${ }^{\$}$ in $\mu \mathrm{M}$ )

\begin{tabular}{|c|c|c|c|c|c|c|}
\hline Sensor & Technique & $\begin{array}{l}\text { Deposition } \\
\text { potential }(\mathbf{V})\end{array}$ & $\begin{array}{l}\text { Deposition } \\
\text { time (s) }\end{array}$ & $\begin{array}{l}\text { Detection } \\
\text { limit }\left(\mu \mathrm{g} \mathrm{L}^{-1}\right)\end{array}$ & $\begin{array}{l}\text { Linear range } \\
\left(\mu \mathrm{g} \mathrm{L}^{-1}\right)\end{array}$ & Ref \\
\hline $\begin{array}{l}\text { Poly(1,5-DAN)/ } \\
\text { MWCNTs/Pt }\end{array}$ & SWASV & -1.2 & 420 & 2.1 & $4-150$ & {$[11]$} \\
\hline $\begin{array}{l}\text { Bi/Nafion/OPPy- } \\
\text { MES/GCE }\end{array}$ & SWASV & -1.2 & 300 & 0.03 & $0.05-35$ & {$[57]$} \\
\hline $\begin{array}{l}\text { AuNP-graphene- } \\
\text { CySH-Bi-GCE }\end{array}$ & SWASV & -1.2 & 800 & 0.05 & $0.5-40$ & {$[58]$} \\
\hline Poly(1,8-DAN)/CPE & DPASV & -0.9 & 600 & 30 & $40-2070$ & {$[53]$} \\
\hline $\begin{array}{l}\text { Bi-Poly }(1,8- \\
\text { DAN)/CPE }\end{array}$ & SWASV & -1.0 & 120 & 0.3 & $0.5-50$ & {$[38]$} \\
\hline Bi/PANI/GCE & SWASV & -1.3 & 120 & $16.5^{*}$ & $25-150^{*}$ & [59] \\
\hline CNFs/Nafion/ GCE & OSWSV & -1.25 & 300 & $0.9^{*}$ & $0.1-0.7^{\$}$ & [51] \\
\hline sGO/PPy-SPE & DPASV & -1.2 & 600 & 0.07 & $\begin{array}{c}1.4-28,28- \\
280 \text { and } 280- \\
14000\end{array}$ & [15] \\
\hline $\mathrm{PPy} / \mathrm{CNF} / \mathrm{CPE}$ & SWASV & -1.2 & 600 & 0.05 & $0.2-130$ & $\begin{array}{l}\text { This } \\
\text { work }\end{array}$ \\
\hline
\end{tabular}

$D P A S V$ differential pulse anodic stripping voltammetry, $O S W S V$ osteryoung square vave stripping voltammetry, GCE glassy carbon electrode, $S P E$ screen printed electrode, $P t$ platinum, 1,5-DAN 1,5-diaminonaphthalene, 1,8-DAN 1,8-diaminonaphthalene, OPPy overoxidation of polypyrrole, $P A N i$ polyaniline, $M E S$ 2-mercaptoethanesulfonate, $s G O$ cysteine functionalized graphene oxide, MWCNTs multiwalled carbon nanotubes, $C y S H \mathrm{~L}-$ cysteine, $A u N P$ gold nanoparticles, $B i$ Bismuth 
Table 2 Recovery and relative standard deviation $(\mathrm{RSD})$ of $\mathrm{Pb}^{2+}$ in the tap water samples using the modified electrode PPy/CNFs/CPE $(n=3)\left({ }^{*}\right.$ Not detected $)$

\begin{tabular}{|c|c|c|c|c|c|}
\hline \multirow{2}{*}{ Samples } & \multicolumn{3}{|c|}{$\mathrm{Pb}^{2+}\left(\mu \mathrm{g} \mathrm{L}^{-1}\right)$} & \multirow{2}{*}{$\begin{array}{c}\text { Recovery } \\
(\%)\end{array}$} & \multirow{2}{*}{$\begin{array}{l}\text { RSD } \\
(\%)\end{array}$} \\
\hline & Original & Added & Found & & \\
\hline Tap water 1 & $\mathrm{ND}^{*}$ & 5 & 4.88 & 97.6 & 1.2 \\
\hline Tap water 2 & $\mathrm{ND}^{*}$ & 10 & 10.15 & 101.5 & 2.1 \\
\hline Tap water 3 & $\mathrm{ND}^{*}$ & 15 & 15.30 & 102 & 2.3 \\
\hline
\end{tabular}

